\title{
El conchero de Cañada Honda I (Aljaraque, Huelva, ESPAÑA): NUEVOS DATOS PARA SU CARACTERIZACIÓN
} CRONOLÓGICA Y TECNOCULTURAL

\section{Cañada Honda I shell-midden (Aljaraque, Huelva, Spain): new data for its chronological and techno-cultural characterization}

\author{
Helena ReIs \\ Universidade do Algarve \\ orcid.org/0000-0001-5873-0928 \\ Pedro Campos Jara \\ Universidad de Huelva \\ orcid.org/0000-0002-5933-8036 \\ Rui SOARES \\ Faculdade de Letras da Universidade de Lisboa \\ orcid.org/0000-0002-4322-7008
}

Recibido: $14 / 02 / 2020$

Revisado: 03/05/2020
Aceptado: 03/05/2020

Publicado: 05/07/2020

\section{RESUMEN}

Los estuarios de los ríos Tinto y Odiel se localizan en la costa suroeste de la Península Ibérica, en el sector noroccidental del Golfo de Cádiz. Los cursos fluviales de ambos ríos atraviesan la provincia de Huelva constituyendo un sistema estuarino en su zona de desembocadura con el Océano Atlántico. Situado en la margen derecha del estuario del Odiel el conchero arqueológico de Cañada Honda (Aljaraque, Huelva), originado en torno a la fase final del último ascenso marino postglaciar (Holoceno), se ha venido considerando un importante establecimiento prehistórico para el estudio del proceso de tránsito de las sociedades cazadoras-recolectoras a aquellas que, en el camino a la sedentarización, desarrollaron estrategias productoras.

En el presente artículo damos a conocer un conjunto de materiales y una datación radiocarbónica de Cañada Honda que viene a reforzar su atribución cronológica-cultural a momentos del Mesolítico Final y Neolítico Antiguo.

\section{Palabras Clave}

Conchero; Flandriense; Mesolítico; Neolítico Antiguo; río Odiel; Aljaraque; Huelva.

\section{ABSTRACT}

Tinto and Odiel estuaries are located on the southwestern coast of Iberian Peninsula, on the north-western part of Golfo de Cadiz. Both rivers cross Huelva province and present an estuarine system on its debouch into Atlantic Ocean. Located on the right bank of Odiel Estuary, Cañada Honda shell-midden (Aljaraque, Huelva), formed around the final phase of the maximum of post-glacial sea-level rise (Holocene), has been considered an important pre-historic site for the study of the transition process from hunter-gatherer societies, those that on their way into sedentarization, develop productive strategies.In this text, we present a set of archaeological materials and a radiocarbon date for Cañada Honda that reinforces its chrono-cultural attribution to a time between Late Mesolithic and Early Neolithic.

\section{KEY WORDS}

Shell-midden; Flandrian; Mesolithic; Early Neolithic; Odiel river; Aljaraque; Huelva. 


\section{INTRODUCCIÓN}

Las primeras descripciones de concheros aparecen asociadas con los daneses køkkenmøddingers. Según la reciente definición que proponen Balbo y otros (Balbo et al., 2011), los concheros son "acumulaciones antropogénicas intencionales de conchas" [traducción de los autores]. Aún así, creemos que es importante distinguir entre concheros (Shell middens) y sitios con acumulaciones de conchas en menores cantidades (Shell bearing sites).

A partir del Mesolítico, el proceso de formación de yacimientos de tipo conchero es habitual en las zonas atlánticas de la Península Ibérica, principalmente en la zona centro y sur de Portugal, en los valles de los ríos Tajo y Sado y en la costa alentejana; en el norte de España, predominan en las costas del mar Cantábrico, en especial en Cantabria y Asturias (Gutiérrez-Zugasti et al., 2011).

En general, los concheros situados en el litoral portugués conforman grandes acumulaciones de conchas que, como en el caso del rio Muge, pueden formar verdaderos montículos en el paisaje. Dichas formaciones antrópicas contienen estructuras de hábitat, como fosos y estructuras de combustión; un variado repertorio faunístico (malacofauna, restos de peces y mamíferos pequeños y medianos); restos botánicos; una industria lítica fuertemente marcada por la presencia de microlitos geométricos (Arias et al., 2016) y, por último, un importante componente funerario (Cunha y Umbelino, 2001; Peyroteo Stjerna, 2016). Cronológicamente, estos yacimientos tienden a desaparecer en los momentos iniciales del Neolítico Antiguo, aunque no lo hacen en su totalidad, ya que pasan a formar parte de un sistema de poblamiento diferenciado, en el que van a aparecer nuevas estrategias económicas en sus formas de vida (Nukushina, 2016,49; Carvalho, 2008).

En el litoral atlántico del sur de España los concheros son muy escasos, en gran parte porque se estima que están sumergidos como consecuencia de la transgresión Flandriense (Muñoz, 2013, 82), predominando el modelo de asentamientos mesolíticos situados al aire libre. No obstante, aunque los concheros se han venido considerando como un fenómeno propio de los litorales del Arco Atlántico también están siendo documentados, en contextos atribuibles al Neolítico Antiguo y Final, en zonas geográficamente más meridionales cercanas al Mediterráneo, como son las costas de Cádiz y Huelva (Op. Cit., 2013).
La evolución holocénica de los últimos 11700 años produjo los cambios más recientes en la morfología litoral del Suroeste peninsular con el ascenso general del nivel del mar, sus últimas fluctuaciones regionales y la mejoría climática, cuyo fenómeno más significativo será la Transgresión Flandriense y el proceso de antropización del sistema natural (Borja, 2013, 83). En relación con dicho evento postglacial, asociado con unas favorables condiciones ambientales y al potencial en la obtención de alimentos que proporcionaba dicho medio fluviomarino, grupos humanos postpaleolíticos que frecuentaban el estuario del rio Odiel van a constituir los primeros concheros arqueológicos que denotan un inicial proceso de semisedentarización.

En Cañada Honda, entre la gran acumulación de origen antrópico de restos de conchas de moluscos marinos con claras evidencias de haber sido procesados para su consumo y posteriormente desechadas, se detectó en su nivel inferior o de base la presencia de industria lítica reveladora de una posible continuidad de las estrategias predatorias propias de los grupos epipaleolíticos presentes en el territorio y cuya tecnología lítica correspondía a las denominadas Industrias de Cantos Tallados del Litoral Onubense (Vallespí et al., 1981, 23-24; Vallespí et al., 1986, 54-55; García y Rodríguez, 1990, 393-396). No obstante, junto a éstas y en el mismo nivel se detectó un utillaje lítico novedoso para dichos contextos más propios de momentos más avanzados como el Mesolítico o el Neolítico Antiguo. Éstas evidencias líticas hasta entonces nada frecuentes en el estuario del Odiel se hacen mucho más patentes en el nivel estratigráfico superior de Cañada Honda en que, aun perviviendo la industria de cantos tallados, aumenta significativamente el microlitismo y se evidencia una mayor diversificación en el utillaje apareciendo además otro tipo de elementos como estructuras siliformes, adobes, restos óseos humanos y de animales y, en menor medida, paredes de cerámicas a mano y una moleta (Borja et al., 1994, 347-348; Martin y Campos, 1995, 15-17).

De aquí que, en el conchero de Cañada Honda, donde hasta el presente no se han realizado excavaciones arqueológicas que completen su investigación, se haya venido admitiendo el constructo de un prístino proceso de neolitización en el estuario del Odiel, como yacimiento que reflejaría un tránsito de la economía cazadora-recolectora a la puesta en práctica de estrategias productoras. 
Hasta el descubrimiento de Cañada Honda, los estudios sobre La Dehesa y El Judío (Piñón y Bueno, 1985, 121ss; Piñón, 1988, 233) y sobre Papa Uvas (Martín, 1985, 186-188; 1986, 312-314; 1994, 182ss) constituían las bases para el conocimiento del proceso de neolitización en el litoral onubense. A partir de década de los '90, con el aumento significativo de localizaciones neolíticas en el estuario del Odiel se fueron aportando diferentes explicaciones evolutivas desde el sustrato postpaleolítico/mesolítico hasta el desarrollo de Neolítico en la zona (Borja et al., 1994, 351; Martin y Campos, 1995, 1014; 1996, 111-113; 1997, 286-288; García et al., 1997. 279; Martín, 1998, 238; Campos y Gómez, 2001).

Ya en el presente siglo, ha aumentado el descubrimiento de nuevos yacimientos en el área del estuario del Odiel a través de la realización de las cartas arqueológicas de Aljaraque y Gibraleón (Campos, 2002, 125-131; 2017, s.p.). Otros trabajos de mayor alcance territorial, aunque centrados en el interfluvio Guadiana-Guadalquivir también han contribuido a la definición general del proceso (Gavilán et al., 2009 , 135ss; 148-9), a los que se suman nuevas revisiones (Martín, 2018, 119ss). En el citado yacimiento de La Dehesa (Lucena del Puerto) se realizó una campaña de excavación en 2008 cuyos resultados, sólo avanzados parcialmente en trabajos de síntesis, están pendientes de su publicación (Vera et al., 2010, 123-4; Camalich y Martín, 2013, 119-122). Recientes excavaciones en La Orden-Seminario (Huelva) han revelado la existencia de estructuras correspondientes al Neolítico Final que sus investigadores sitúan en el III milenio a.C. (Garrido y Vera, 2015, 157).

Con los progresos de la investigación arqueológica en la paleodesembocadura de los ríos Tinto y Odiel se está constatando que nos encontramos en un espacio de especial interés para el conocimiento del proceso de tránsito de la economía cazadorarecolectora a la de producción, así como de la evolución de las sociedades neolíticas en el territorio dada la presencia de diferentes tipos de yacimientos cuyas cronologías se extienden entre el VI y III milenios a.C.

\subsection{Evolución reciente del paleoestuario de los ríos Odiel y Tinto}

Dentro de los diferentes humedales y espacios marismeños del Golfo de Cádiz, los estuarios de los ríos Odiel y Tinto constituyen una extensa zona húmeda situada en la costa SO de la Península Ibé- rica que geológicamente aparece relacionada con la del resto del litoral suroccidental peninsular. Ambos cursos fluviales conforman sus respectivos estuarios y se unen poco antes de su zona de desembocadura en el Océano Atlántico. Este sistema se desarrolla sobre un sustrato constituido por materiales detríticos de edad neógeno-cuaternaria (Viguier, 1974; Clemente et al., 1985, 339). En estas latitudes, a partir de la última de las pulsaciones frías del ciclo climático Cuaternario, hace 18.000 años aproximadamente (Paskoff, 1985, 15-19), se produjo un acusado descenso del nivel del mar en más de 100 m., un cambio de régimen pluvial con el aumento de las precipitaciones y la individualización de las cuencas hidrográficas actuales. Como consecuencia aumentó la capacidad erosiva de la escorrentía superficial, cuyos principales cauces excavaron profundos estuarios que hoy en día encuentran prolongación en la plataforma continental, a la vez que, con este proceso, se desmantelaban parte de las formaciones pliocuaternarias recientemente emergidas (Ojeda, 1989, 125).

Posteriormente, a partir del $16000 \mathrm{BP}$, a causa de la fundición de grandes masas de hielo ocasionada por el deshielo postwürmiense, se inicia el proceso de subida del nivel del mar dio lugar en las costas suroccidentales de la Península Ibérica a la invasión de sus estuarios por las aguas marinas y a un modelado interno con continuos entrantes y salientes, muy definidos, sobre los que los procesos morfodinámicos superficiales comenzaron un lento proceso geológico de regularización. Los cursos bajos de los ríos que desembocan en esta franja litoral comenzaron a ser invadidos por el mar hace aproximadamente 10.000 años (Borrego et al., 1999, 772) alcanzándose un nivel del mar estable y similar al actual sobre los 4.500 años BP cuando se hacen patentes en los estuarios la presencia de metales pesados en los sedimentos provenientes de la explotación de minas o afloramientos mineros situados en la cuenca de dichos ríos (Nocete et al., 2004-5, 39-40; 43; Delgado et al., 2012, 132, 138). Entre 11600-7800 BP, a causa de oscilaciones climáticas con pulsaciones frías y áridas, se desarrollaron una serie de episodios en el ritmo de aceleración y desaceleración en el aumento del nivel del mar, hasta que se produce la Transgresión Flandriense, considerada la última elevación del nivel del mar.

En su máximo transgresivo (6500-6000 BP), en que se origina un posicionamiento relativo del nivel 
del mar de unos $2 \mathrm{~m}$. por encima de su posición actual, se produce su máximo avance hacia tierra y la conformación de las primeras barreras estuarinas (Ojeda, 1989, 125-126; Dabrio et al. 1999, 277; Morales y Ojeda 2010, 33).

A. Horowitz (1981) en su exploración de una amplia zona que comprende prácticamente todo el sector costero de la provincia de Huelva, realizó una intensa recogida de muestras y análisis de polen de la fase climática Dryas Reciente, que complementó con el estudio palinológico de turba representativas de niveles de agua subterránea del Holoceno, distintas del actual. Fruto de estos trabajos propuso la existencia de un ambiente climático más húmedo durante el periodo Atlántico, y con niveles de agua subterránea más altos que el actual, donde predominaba un paisaje con una vegetación más densa, fundamentalmente formada por bosques de encinas, con ausencia de pinos, y con una vegetación de campo abierto, igualmente mucho más desarrollada y una total ausencia de marismas saladas (Horowitz, 1981, 205-216). Por tanto, las condiciones climáticas existentes desde el Holoceno superior favorecieron los asentamientos humanos en el paleoestuario Tinto-Odiel, momento en que tiene lugar la ocupación de Cañada Honda por parte de un grupo humano.

\subsection{Precedentes de antropización del territorio}

Las evidencias paleolíticas en el entorno de Cañada Honda están atestiguadas en los yacimientos Río Odiel I y Manzorrales, cuyos contextos líticos superficiales se diseminan sobre las terrazas medias y bajas del río Odiel (García y Castiñeira, 1987, 32; Campos, 2002, 124). La industria lítica de estos grupos humanos corresponde a poblaciones de cazadores-recolectores, aunque hasta el presente no han sido documentados zonas de hábitat ni espacios de consumo de fauna terrestre ni marina. La vida de estos pobladores prehistóricos debió transcurrir en el entorno de valles fluviales próximos al litoral atlántico durante la última fase glacial. En dicha etapa el nivel del mar alcanzó su posición más baja, estando la línea de costa mucho más alejada que en el periodo de formación de los estuarios holocénicos.

Para datar dichos yacimientos se ha establecido un gran arco cronológico que va desde el Pleistoceno Superior (Paleolítico Medio) hasta el Holoceno,
Paleolítico Superior final-Epipaleolítico (García y Castiñeira, 1987, 38). La industria lítica característica de los yacimientos Río Odiel I y Manzorrales, presenta técnicas de talla propias del Paleolítico Medio, muy extendidas por el territorio litoral y prelitoral de Huelva, encontrando paralelos con otros yacimientos posiblemente contemporáneos, situados en espacios relacionados con el estuario Tinto-Odiel: Terrazas del Odiel II-III y El Grillito (Gibraleón), La Dehesa (Lucena del Puerto), Río Piedras (Cartaya), El Monturrio (Moguer), El Apeadero (Niebla) y Arroyo Candón (Beas) (García y Castiñeira, 1987, 38).

Sondeos recientes realizados en diferentes áreas del yacimiento Río Odiel I (Aljaraque), entre las denominadas terrazas no 3 y 4 (T3-T4) del río Odiel, atribuyen una antigüedad para dichas terrazas que va desde el Pleistoceno Medio Final (Moro 2009, 552) al Pleistoceno Final (Campos 2018, 58), a partir del estudio de la técnica de talla de la industria lítica propia del Paleolítico Medio recuperada en estos sondeos. También, en un análisis reciente de materiales observados en una gravera próxima al yacimiento Río Odiel I sitúan la citada terraza T3 del Odiel en el Pleistoceno Superior (Rodríguez y Vera, 2016, 228).

Ajustado a momentos tardíos del Pleistoceno Superior Final y la primera mitad del Holoceno se documentó la existencia de una fase o facies postpaleolítica denominada, indistintamente, Industrias Tardías de Cantos Tallados del Litoral Onubense o Complejo de Cantos Tallados del Litoral Onubense, de las que sus primeros investigadores ya advirtieron de la existencia de contextos líticos cronológicamente mucho más recientes y con unas características de talla específicas, en parte diferenciables, que en ocasiones se localizaban revueltos a nivel superficial con las evidencias paleolíticas más antiguas (Vallespí et al., 1981; Vallespí et al., 1986, 54, 55; García y Rodríguez, 1990, 393-397). Dicha industria lítica se adscribe a momentos finipaleolíticos o de inicios del Holoceno. Entre las características de dicha industria destaca su elaboración sobre cantos de cuarcita de grano fino y pequeño tamaño, con gran representación de técnicas de talla unifacial y centrípeta, seguidas de la bifacial y de manera escasa la multidireccional, siendo el tipo de núcleo dominante el discoide, apareciendo también una industria sobre lascas muy poco elaboradas, predominando las de semidescortezado y 
la de útiles sobre lasca (García y Rodríguez, 1990, 393-397). Los yacimientos generalmente se localizan en depósitos aluviales de terraza, en espacios litorales o penetrando algo hacia el interior por las desembocaduras de los ríos actuales. Localizaciones que se extienden por toda la franja litoral y prelitoral de la provincia de Huelva (Castiñeira et al., 1988, 22; Castiñeira et al., 1989, 61). Incluso se ha planteado una posible relación de las industrias de cantos tardíos del litoral onubense con las industrias de cantos tallados portuguesas englobadas bajo el término "Mirense" (Raposo, 1994, 62-65).

Evidencias arqueológicas de las industrias tardías de cantos tallados han venido siendo constatadas también en diferentes prospecciones superficiales y sondeos arqueológicos más recientes realizados en el municipio de Aljaraque, como en el yacimiento Rio Odiel I y en Manzorrales (Campos, 2002, 123-4; Moro, 2009, 1620-1; Batanero, 2016, 12; Campos, 2018, 29-30).

En relación con la abundante presencia y dispersión de las industrias finipaleolíticas por amplios espacios del litoral onubense y, en particular, en el reborde de estuario de los ríos Tinto y Odiel, se ha sostenido que constituyen el resultado de una realidad socioeconómica de amplia pervivencia temporal en el territorio, basada esencialmente en factores de estabilización, geológicos, económicos y culturales, con estrategias predatorias de aprovechamiento del medio que habrían de convivir y posteriormente evolucionar a estrategias económicas y de hábitat como el modelo representado por los "concheros", favorecidos por el contexto ecológico que, además, conformaba un extenso espacio de captación de recursos (Martín y Campos, 1995, 13; 18).

\section{El conchero de Cañada Honda.}

\section{CONTEXTO GEOGRÁFICO Y CARACTERIZACIÓN}

Está situado al N. de la localidad de Corrales (Aljaraque, Huelva), en la margen derecha del rio Odiel a una cota de entre $+4,5$ y +6 m.s.n.m., sobre una terraza aluvial baja (T-2) de la formación geológica denominada Terrazas del Odiel (Cáceres, 1992, 70; 72)(Fig.1). Los materiales que conforman la terraza fluvial donde se sitúa el yacimiento son relativamente recientes, con edades comprendidas entre el Neógeno y el Cuatenario, y están formados por gravas, arenas, limos y arcillas. Infrayacentes a estos materiales se encuentran las potentes margas azules del Mioceno que no afloran en la zona pero que se han documentado en sondeos cercanos más profundos (Aguilar et al., 2019).

El relieve general de la zona es relativamente llano con una baja pendiente en que se suceden valles y lomas surcados por una red de drenaje bastante encajada que vierte hacia las marismas del río Odiel. Por su lado $\mathrm{N}$ el yacimiento se ubica junto a un arroyo también muy encajado que vierte al Estero del Fraile, uno de los brazos de la margen derecha del Odiel, formando una ensenada, denominada Cañada Honda, que da nombre a la localización arqueológica (Fig.2). La parte mejor conservada del conchero ocupa una superficie de unos $400 \mathrm{~m}^{2}$ sobre un suave montículo. En sus espacios colindantes los restos arqueológicos también aparecen en determinados espacios destruidos o semidestruidos por una cantera de áridos vecina, colindante por su sector S, que se calcula hubo de arrasar más del cincuenta por ciento de la superficie total del conchero (Borja et al., 1994, 341; Martín y Campos, 1995, 15). En su entorno inmediato existe cierta dispersión de restos líticos superficiales que se hacen visibles en una extensión de unos $3500 \mathrm{~m}^{2}$, sobre espacios alterados por la acción antrópica que, posiblemente, debieron formar parte del yacimiento (Beltrán et al., 1997, 272; Campos, 2002, 127-129).

En el estado actual de nuestros conocimientos Cañada Honda se prefigura como un asentamiento humano semisedentario, o en proceso de sedentarización, con una actividad económica volcada en la recolección y consumo de moluscos, cuyo registro fósil, extensión del yacimiento y potencia estratigráfica denotan la importancia que llegó a adquirir la obtención y consumo de dichos recursos marinos por parte del hombre a lo largo de un periodo prolongado de tiempo. Las principales especies documentadas corresponden a bivalvos y gasterópodos que, en muchos casos, constituyen especies que se siguen consumiendo en la actualidad. Entre los bivalvos se han documentado las siguientes especies: Crassostrea angulata; Venerupis pullastra; Venerupis decussata; Cerastoderma edule, C. glaugun, Tellina, Solen y Ostreas. Entre los gasterópodos abundan las Cerithium rupestre; $M u$ rex brandaris y Murex trunculus (Borja et al., 1994, 343-344; Martin y Campos, 1995, 16).

Tras su consumo in situ, las conchas se acumularon en el mismo espacio de hábitat formando un extenso montículo de fuerte compactación debido a la descomposición del carbonato cálcico, con zo- 

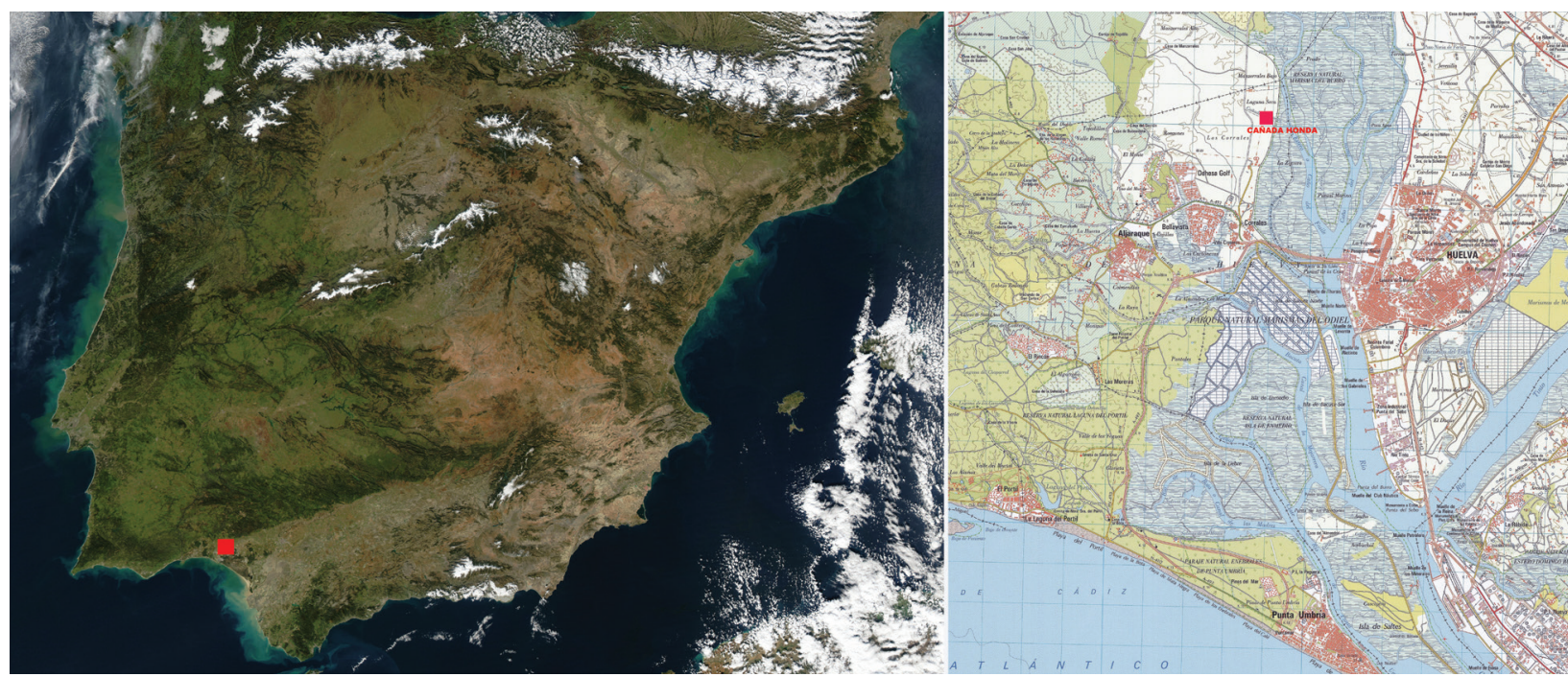

Fig. 1. Localización del yacimiento de Cañada Honda en el Estuario del Odiel (Huelva, España).

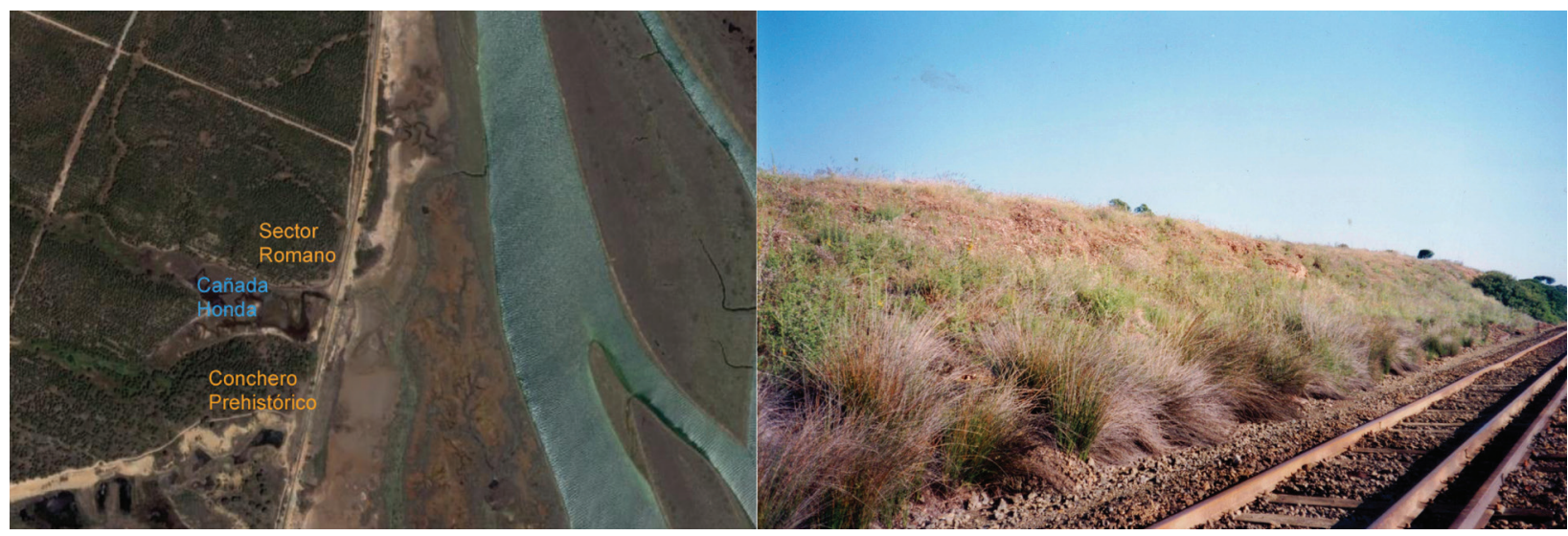

Fig. 2. A la izquierda: emplazamiento del conchero de Cañada Honda a orillas del rio Odiel. A la derecha: vista general desde el S.

nas de hasta $1,5 \mathrm{~m}$. de espesor, donde se ha detectado numeroso utillaje lítico y restos de talla, adobes, que en algunos casos forman estructuras siliformes, muy escasos fragmentos cerámicos a mano y algunos restos óseos humanos. El espesor de este afloramiento antrópico es muy variable, entre $0,40 \mathrm{y}$ $1,5 \mathrm{~m}$, rellenando también pequeñas irregularidades topográficas y creando a techo una zona amesetada que hubo de descender suavemente hacia la línea de costa, desconociéndose además la extensión del yacimiento bajo las actuales marismas (Figs.3,4,5).

En el yacimiento es muy patente la presencia de industria lítica microlaminar, con presencia de raspadores, buriles, laminillas y microlitos sin abandonar el uso de otros artefactos típicos de periodos precedentes, como los grandes cantos tallados. Evidencias que pueden apreciarse en la estratifica- ción visible en su vertiente E. debido al corte de la trinchera del ferrocarril, casi vertical, efectuada en la terraza por el trazado del ferrocarril minero Tharsis-Río Odiel, así como en los cortes efectuados por la citada explotación de graveras en su parte meridional.

Desde su descubrimiento y posterior publicación se ha venido considerando el conchero de Cañada Honda como un asentamiento humano donde posiblemente se produjo la transición de las sociedades nómadas cazadoras-recolectoras del Epipaleolítico/ Mesolítico a las que inician el proceso de sedentarización y producción de alimentos en el Neolítico (Martín y Campos, 1995, 18). En la estratigrafía apreciable en la trinchera del ferrocarril, que sirvió para conocer inicialmente la potencia estratigráfica del yacimiento, se ratificó la existencia de al menos 


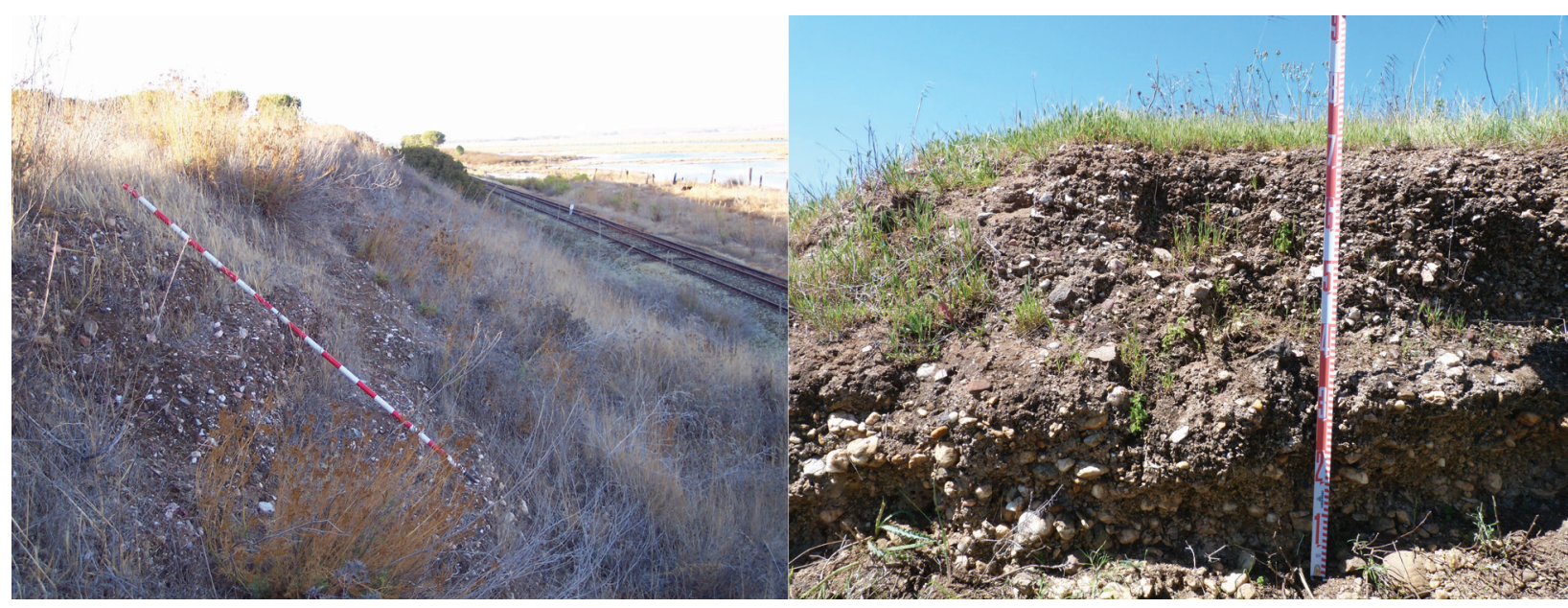

Fig. 3. Detalle del conchero de Cañada Honda apreciable en la trinchera del ferrocarril Tharsis-Rio Odiel. En la fotografía de la izquierda, al fondo, las marismas de este río.

dos niveles en la estratigrafía del conchero (Borja et al., 1994, 345-348). En el nivel inferior los restos malacológicos aparecen entremezclados con la industria lítica tallada compuesta por grandes artefactos y otros, en menor medida, de factura microlítica, mientras que en el superior, más próximo a la superficie del terreno, fueron observables entre las conchas, además de patrones líticos similares a la fase anterior una mayor especialización en la talla de los instrumentos con mayor presencia microlítica principalmente elaborada en sílex, algunas estructuras siliformes de adobe o barro cocido en los perfiles de cortes efectuados en el terreno y restos óseos humanos (Martín y Campos, 1995, 15; Borja et al., 1994, 348) (Fig.4).

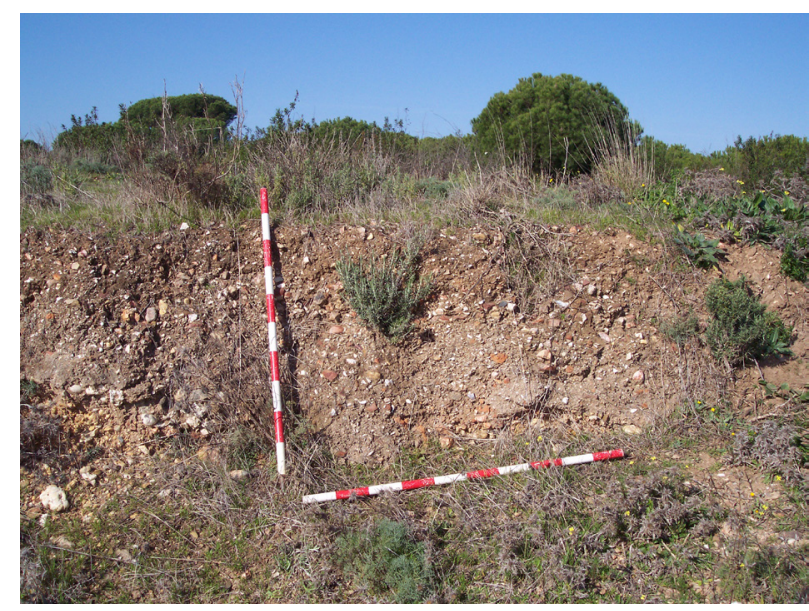

Fig. 4. Detalle de un corte con posibles estructuras siliformes.

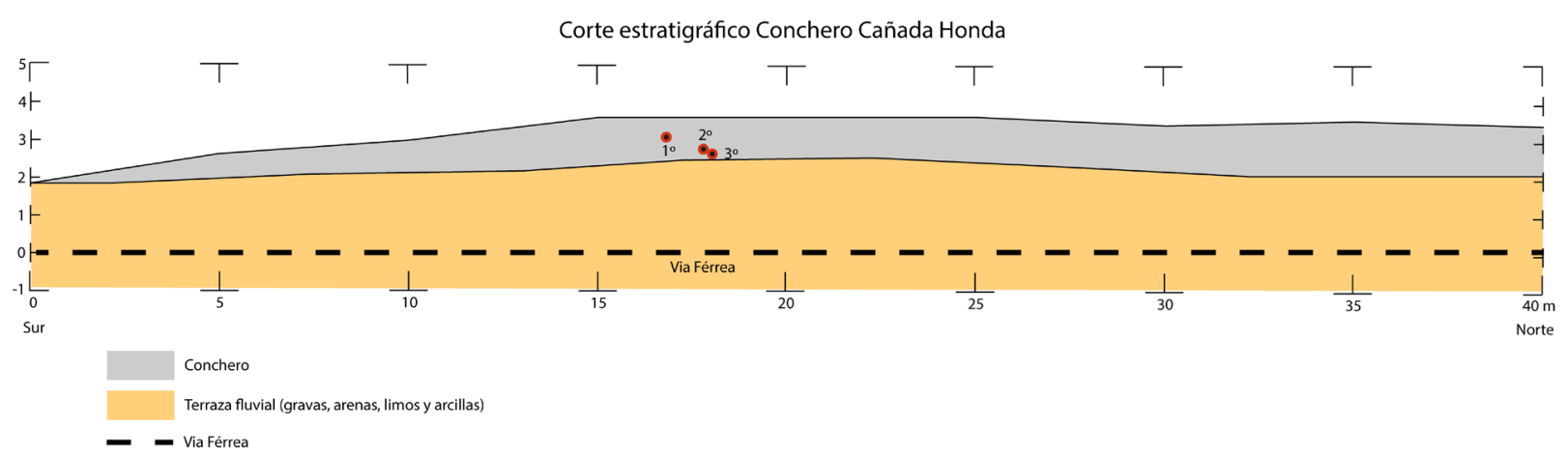

Fig. 5. Perfil topográfico genérico a partir del corte existente en la vertiente E del conchero de Cañada Honda con indicación de los puntos de toma de muestras de conchas. Nivel 1: presencia de conchas más completas y cantos de tamaño más grande, completos y fracturados. Este nivel aparentemente entra en contacto con la superficie. Nivel 2: en su parte superior hay presencia de adobes que parecen formar alineaciones. Nivel 3: Nivel de base del conchero, que puede corresponder a un paleosuelo. 


\begin{tabular}{|c|c|c|c|c|c|c|c|c|c|}
\hline Matéria-Prima/Categoria & Chert & Grauvaca & Indet. & Cuarcita & Cuarzo & Roca Silic. & Sílex & Esquistosilc & Total \\
\hline Núcleos & 1 & & 1 & 4 & & 11 & 3 & & 20 \\
\hline Flancos de núcleo & & & & 2 & & & & & 2 \\
\hline Fragmento/Flanco & & & & & & 2 & & & 2 \\
\hline Material prep. Reaviv. & & & & 2 & & & & & 2 \\
\hline Productos de lascado & 1 & 5 & 7 & 14 & 1 & 4 & 6 & & 38 \\
\hline Laminillas & & & 2 & 1 & & 2 & 5 & & 10 \\
\hline Láminas & & & 1 & & & & & & 1 \\
\hline Lascas & 1 & 5 & 4 & 13 & 1 & 2 & 1 & & 27 \\
\hline Útiles & 3 & 1 & 8 & 10 & & 5 & 16 & 1 & 44 \\
\hline Fragmento indeterminado & & & 1 & 2 & & & & & 3 \\
\hline Fragmento & 1 & & 4 & 3 & & & & & 8 \\
\hline Total general & 6 & 6 & 21 & 37 & 1 & 22 & 25 & 1 & 119 \\
\hline
\end{tabular}

Tabla 1. Distribución de índices tecnológicos según las materias primas.

Cañada Honda se asienta sobre la citada terraza baja (T2) de la formación geológica de origen fluvial denominada Terrazas del Odiel, constituida por graveras cuaternarias en las que las clasificadas de tipo medio alcanzan en esta zona una altitud máxima de $22 \mathrm{~m}$ sobre el nivel del mar. Cáceres les atribuye una edad del Pleistoceno Superior Final (Cáceres, 1999, 185-186). Según este autor, en la actualidad los niveles bajos de dichas terrazas (T1) desaparecen entre los sedimentos y marismas del
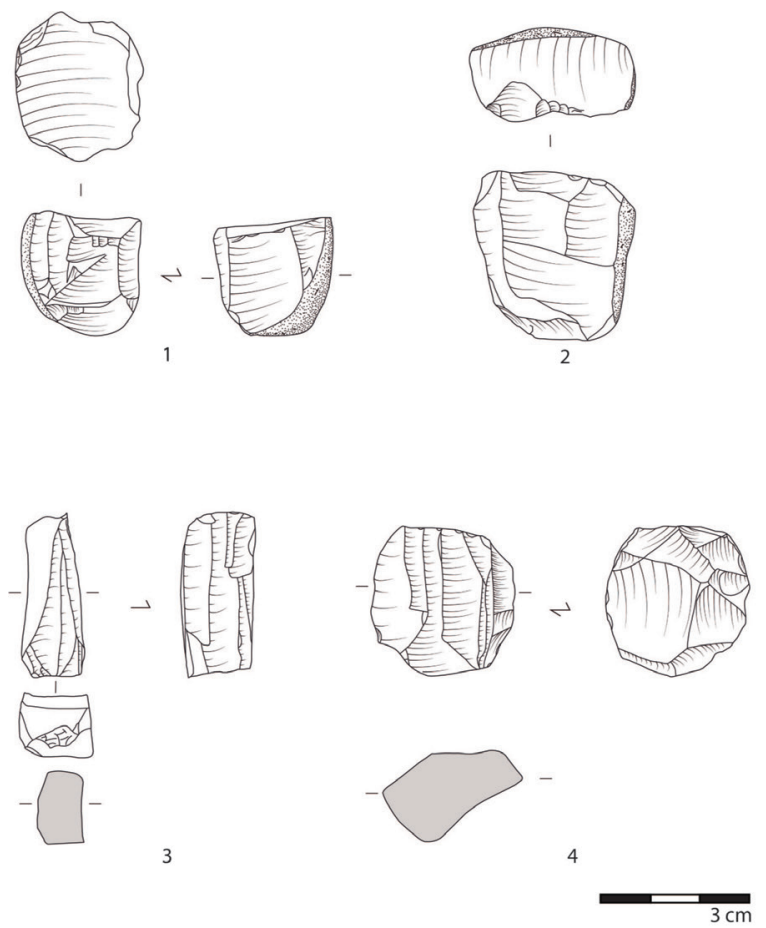

Fig. 6. Industria lítica tallada: núcleos y lascas. mismo río y corresponden al final del Pleistocenoprincipios del Holoceno (Tardiglaciar-Holoceno).

Entre el suave relieve que presenta en este sector las terrazas fluviales del Odiel se inserta la red de drenaje cuaternaria que principalmente vierte al propio río Odiel o a alguno de sus brazos. Ésta pequeña cuenca dendrítica que vierte en la margen derecha del río está constituida por arroyos que, generalmente, se ensanchan en su zona de desembocadura en el propio Odiel conformando,
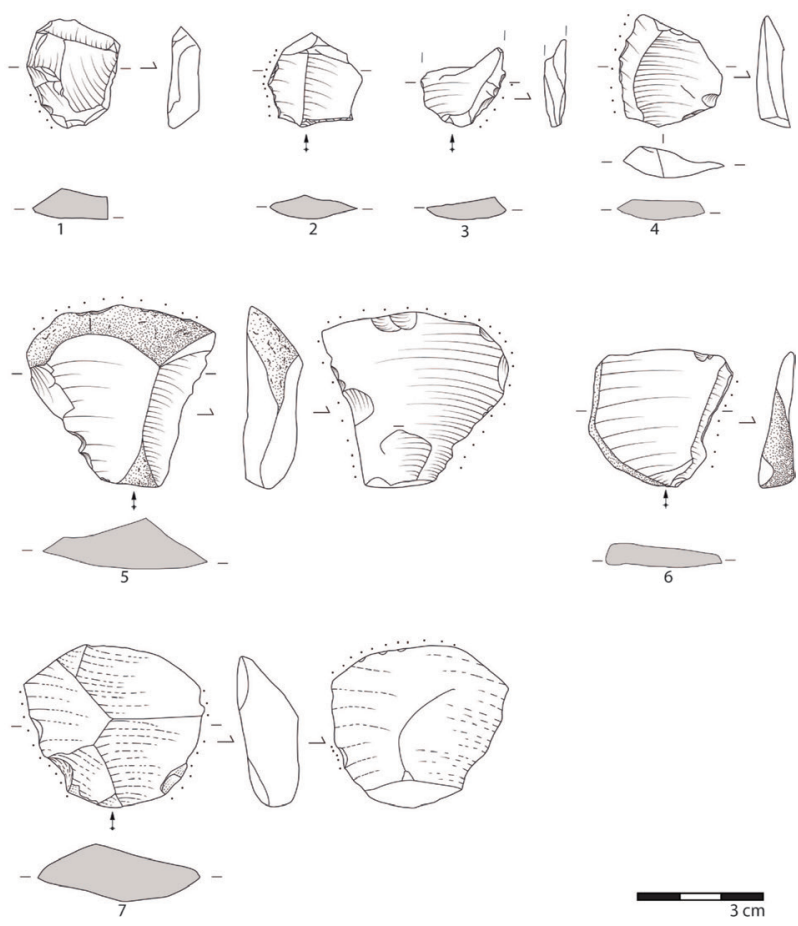


\begin{tabular}{|c|c|c|c|c|c|c|c|c|}
\hline Tipologia & Chert & Grauvaca & Indet. & Cuarcita & $\begin{array}{l}\text { Roca } \\
\text { Silícea }\end{array}$ & Sílex & Esquisto silicoso & Total \\
\hline Con retoque marginal & & 1 & 2 & 2 & & & 1 & 6 \\
\hline Muesca & & & & & & 1 & & 1 \\
\hline Lámina de dorso abatido & & & & & & 2 & & 2 \\
\hline $\begin{array}{l}\text { Piezas con señales } \\
\text { de uso }\end{array}$ & 3 & & 4 & 6 & 5 & 12 & & 30 \\
\hline Raedera & & & & 1 & & 1 & & 2 \\
\hline ¿Raspador? / Con retoque marginal & & & 1 & 1 & & & & 2 \\
\hline Segmento & & & 1 & & & & & 1 \\
\hline Total general & 3 & 1 & 8 & 10 & 5 & 16 & 1 & 44 \\
\hline
\end{tabular}

Tabla 2. Clasificación tipológica del utillaje según las materias primas.

en la actualidad, cañadas y pequeños conos o ensenadas, hoy colmatados de sedimentos y sólo cubiertos por una lámina de agua en la pleamar. Los más próximos a nuestra localización son Cañada Honda, que le da nombre al yacimiento, arroyo de Manzorrales por el norte y por el sur la cañada de La Almaína.

Este espacio ribereño, que en la actualidad forma parte del espacio protegido denominado Paraje Natural Marismas del Odiel, se extiende desde el $\mathrm{N}$ a partir del municipio de Gibraleón, a partir del cual el río Odiel se ensancha notablemente y se hace más sinuoso discurriendo por una amplia superficie deltaica subdividiéndose, a la vez, en canales meandriformes, esteros y caños, que se abren paso entre marismas salobres sometidas a la influencia mareal. En su discurrir se une con las aguas del estuario del río Tinto poco antes de su desembocadura en el océano Atlántico (Fig.1).

La transformación más reciente del espacio donde se sitúa Cañada Honda ha estado condicionada por dos grandes impactos: por un lado, la explotación de áridos de la vecina "Cantera de Manzorrales”, que llegó a afectar gravemente al conchero de Cañada Honda por su vertiente S, quedando arrasado el cincuenta por ciento de su superficie total (Borja et al., 1994, 341; Martín y Campos, 1995, 15), y por otro, la construcción del ferrocarril minero Tharsis-Río Odiel. Las obras de dicho ferrocarril, concebido para trasladar el mineral desde las minas de Tharsis (Alosno, Huelva) hasta el muelle de carga en la ría de Huelva, concluyeron en 1870 (Fig. 2). Dichos trabajos des- montaron una parte significativa de la loma donde se sitúa el yacimiento, lo que hace que en la actualidad presente un corte casi vertical a orillas de las marismas del estuario del Odiel (Martín y Campos, 1995, 15) (Fig. 3). Además, esta obra al rebajar también la zona situada a cota más baja de la terraza fluvial suprimió la prolongación del yacimiento en su declive natural hasta la ribera del estuario. Junto al conchero de Cañada Honda, algo más al Norte y separado por una pequeña ensenada fluviomarina colmatada de sedimentos, se localiza un pequeño hábitat portuario de época romana denominado Cañada Honda II (Campos, 2002, 127; Campos y Pérez, 2018, 514-515).

\section{LA CULTURA MATERIAL ${ }^{1}$}

\subsection{La industria lítica}

3.1.1 Metodología de la industria lítica tallada

Para el estudio de la industria lítica tallada se ha adoptado la metodología analítica basada en los criterios propuestos por G.E.E.M. (1969); Inizan et al., (1999); Tixier et al., (1980), Zilhão (1997); Carvalho $(1998,2008)$ y para las restantes categorías líticas en Diniz (2007).

1 El conjunto de materiales y muestras óseas y malacológicas aquí estudiados fueron documentados con motivo de los trabajos de campo para la "Elaboración de documentación técnica para la Inscripción en el Catálogo General de Patrimonio Histórico de Andalucía como Bien de Interés Cultural (B.I.C.) con categoría de Zona Arqueológica, del yacimiento arqueológico de Cañada Honda, término municipal de Aljaraque (Huelva)” (Campos, 2007). 


\subsubsection{Materias primas}

El análisis del pequeño conjunto correspondiente a la industria lítica tallada de Cañada Honda documentada en superficie consta de 119 piezas. Se compone principalmente de útiles, lascas, restos de talla y núcleos (Tabla 1).

El análisis preliminar y macroscópico nos permitió concluir que las materias primas con mayor representación en el conjunto son las cuarcitas, el sílex y otras rocas silíceas, incluidas aquí aquellas de las que no se ha podido obtener una clasificación precisa así como un número no especificado de indeterminados. También forman parte de este conjunto, el chert, la grauvaca, el cuarzo, el esquisto silíceo y la cuarcita de grano fino.

En cuanto a la disponibilidad de materias primas, cabe señalar que todas ellas son locales y se encuentran en los niveles superiores de las terrazas cuaternarias, con excepción del sílex, cuya procedencia no se ha definido todavía en los contextos litorales de Huelva. No obstante, se han realizado varios estudios en torno a los posibles lugares de procedencia de materias primas en la zona occidental de Andalucía (Domínguez-Bella, et al., 2016, 344-349).

\subsubsection{Núcleos}

Se han identificado un total de 20 núcleos (Fig. 6) y dos flancos de núcleo. La presencia de córtex en el conjunto es superior (cortical $n=2$, semicortical $n=5$, vestigial $n=4$ ), en comparación con el número de especímenes sin córtex $(\mathrm{N}=4)$. Los especímenes con córtex presentan una superficie de soporte de canto rodado, o con partes de roca madre rodada y consistente.

El grupo de rocas silíceas está compuesto por 16 elementos, 14 de los cuales están completos. En cuanto a la morfotipología, este grupo tiene sobre todo plataformas prismáticas $(\mathrm{N}=6)$, globulares $(\mathrm{N}=3)$ y astilladas $(\mathrm{N}=3)$, con plataformas lisas $(\mathrm{N}=6)$ y facetadas $(\mathrm{N}=4)$, con extracciones bipolares $(\mathrm{N}=5)$, múltiples $(\mathrm{N}=5)$ y unipolares $(\mathrm{N}=4)$, donde se observan lascas y láminas.

El resto de elementos están realizados en cuarcita y en rocas indeterminadas, entre los que sólo 4 están completos. La presencia de córtex es dominante (cortical $n=3)$ y semicortical $(n=2)$. Este conjunto está representado por elementos con extracción sobre cantos, en su mayoría unipolares, que pueden corresponder a tipologías chopping tool.

\subsubsection{Productos de talla}

Entre los productos de talla encontramos una mayoría de lascas y esquirlas $(\mathrm{N}=27)$, seguidas de laminillas $(\mathrm{N}=10)$ y sólo una lámina (Figs. 5, 6).

Las laminillas están realizadas en sílex y otras rocas silíceas, ya que estas rocas son las más adecuadas para la obtención de productos laminares, más alargados. En cuanto a sus características, se observó que la mayoría corresponden a talones facetados $(\mathrm{N}=8)$, bulbos pronunciados $(\mathrm{N}=19)$, perfiles rectos $(\mathrm{N}=17)$, secciones triangulares $(\mathrm{N}=13)$ y trapezoidales $(\mathrm{N}=12)$, bordes paralelos $(\mathrm{N}=19)$, ondas de percusión no visibles $(\mathrm{N}=12)$, ausencia de bulbo de percusión ( $\mathrm{N}=9$ ).

Las lascas (Fig.6) están realizadas principalmente en cuarcita, sílex y otras rocas silíceas. En cuanto a sus características, se observaron talones corticales $(\mathrm{N}=26)$ y lisos $(\mathrm{N}=11)$, perfiles rectos $(\mathrm{N}=40)$, otras secciones $(\mathrm{N}=28)$ y triangulares $(\mathrm{N}=13)$, bordes paralelos $(\mathrm{N}=16)$, entre otras morfologías sin apreciar tendencias preponderantes y bulbos de percusión no visibles $(\mathrm{N}=30)$.

\subsubsection{Utillaje}

El utillaje estudiado (Figs. 6, 8 y Tabla 2), realizado, principalmente sobre soportes silíceos consiste principalmente en lascas y láminas. De éstas, en primer lugar, se han identificado piezas con huellas de uso $(\mathrm{N}=30)$, observables macroscópicamente en su mayor parte en el borde izquierdo o en ambos bordes. En segundo lugar, hay piezas con retoques $(\mathrm{N}=6)$, principalmente cortos, rectilíneos y semiabiertos. Además de éstas, se registraron también un raspador, un posible raspador, láminas con el borde abatido y un microlito geométrico (segmento). Este último está retocado en uno de sus bordes presentando una posible fractura de impacto en un extremo, lo que sugiere su uso como proyectil.

\subsubsection{Piezas de preparación y reavivado}

Sólo se han documentado dos piezas para la preparación y el reavivado de piezas talladas en cuarcita, conservando parte del córtex.

\subsubsection{Piezas macrolíticas y otras categorías}

Algunos elementos clasificados como núcleos representan una industria macrolítica llevada a cabo sobre cantos de cuarcitas. Otros ejemplos de esta industria macrolítica son también lascas de grandes dimensiones realizadas igualmente en cuarcitas (Fig.9).. 

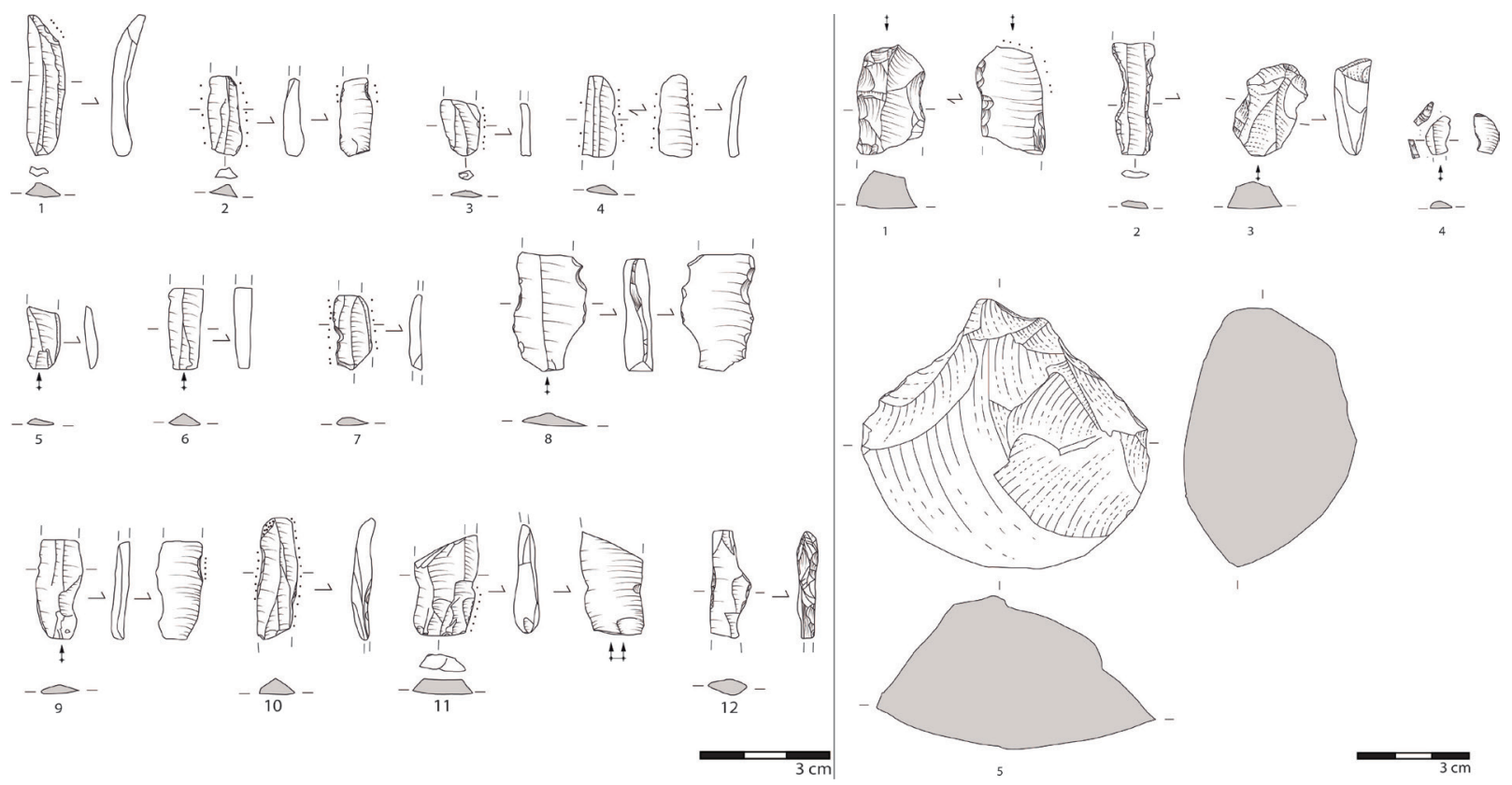

Fig. 7. Industria lítica tallada. Útiles.

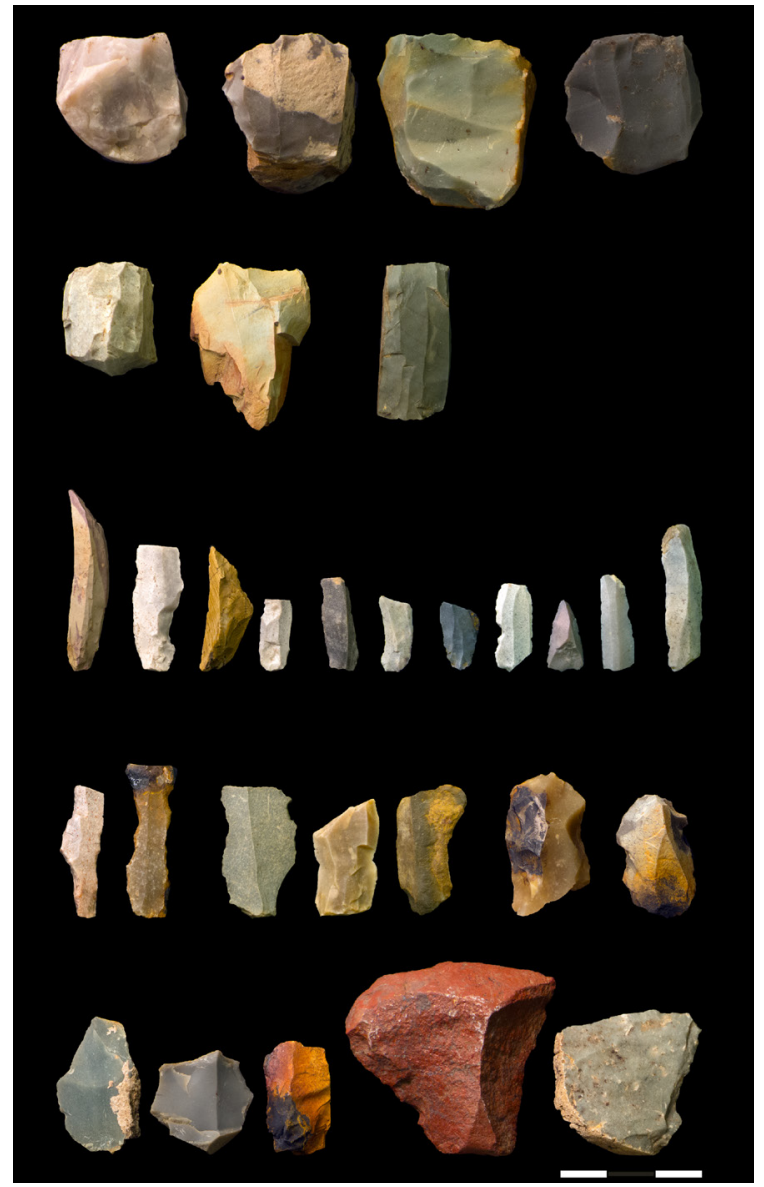

Fig. 8. Fotografía de útiles líticos tallados: núcleos, lascas, láminas y laminillas, retocadas y sin retoque.

\subsubsection{Resumen}

De forma general, la industria lítica aquí descrita se puede dividir en dos grandes grupos; por un lado, industria realizada en sílex y otras rocas silíceas de grano fino y, por otro, industria sobre rocas de grano grueso. La talla de rocas silíceas de grano fino está basada en la explotación de pequeños núcleos, particularmente de sílex, para obtener productos alargados (láminas y laminillas), a partir de los cuales se fabrican útiles, ya sea por medio de retoques o para ser utilizados directamente en bruto. La talla de grano grueso se presenta principalmente en lascas y en cantos tallados de cuarcitas.

Las características tipológicas del utillaje lítico tallado de Cañada Honda parecen apuntar a una industria que encaja en el Mesolítico Tardío/Neolítico Antiguo. Al tratarse de un conjunto que proviene de recogidas superficiales, no es posible obtener un diagnóstico cronológico más detallado, que podría hacerse, en el caso de un conjunto contextualizado, mediante la asociación de presencias y ausencias de características tecnológicas y tipológicas en un conjunto cerrado.

No obstante, las tipologías presentes en Cañada Honda encuentran paralelismos con las industrias típicas de los concheros portugueses, como los situados en el Sado, donde los recursos líticos disponibles en sus proximidades se utilizan para la producción de útiles principalmente lascas y lá- 

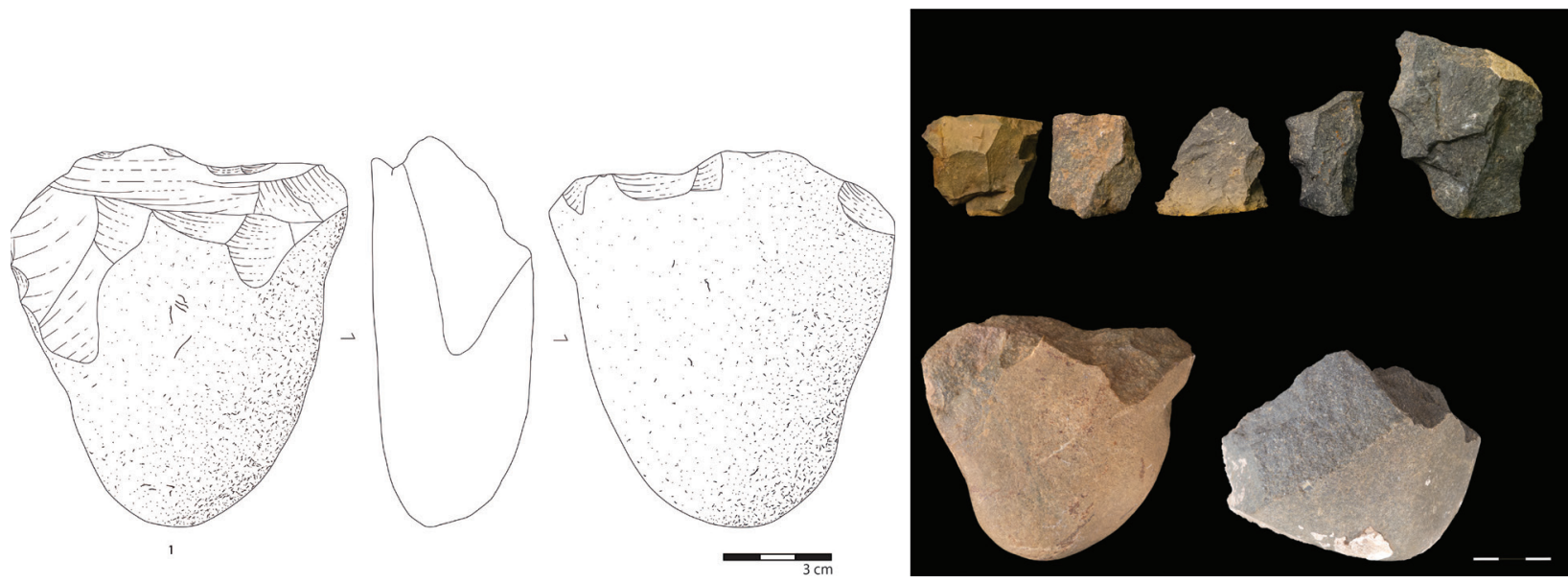

Fig. 9. Material macrolítico: lascas y cantos tallados en cuarcita y otras rocas de grano grueso.

minas, además de una presencia determinante, que puede variar dependiendo del sitio y/o del contexto estratigráfico, de microlitos geométricos (Nukushina, 2012,78-92; Diniz y Nukushina, 2014, 35; Marchand, 2001, 67; Araújo, 1998-1999, 131-137).

\subsection{Otras categorías de material arqueológico}

Dentro de este grupo se han documentado dos cantos de granito con marcas de percusión que evidencian su uso. También se ha comprobado la presencia de cerámica, consistente en dos fragmentos lisos realizados a mano, con coloración naranja y marrón y con desgrasantes minerales de color negro en su pasta y posiblemente mica. Asimismo, se verificó la presencia de nódulos de arcilla (icocidos?), que, en ocasiones, presentan rastros de concreciones calcáreas (Fig. 9).

El dilema de la presencia de cerámica en los concheros es uno de los elementos más problemáticos en su interpretación cronológica, ya que ésta generalmente constituye un ítem característico del "paquete neolítico" tradicional. Diferentes interpretaciones relacionadas con los análisis estratigráficos vienen produciendo intensos debates sobre el proceso de neolitización en los concheros portugueses, lo que plantea interrogantes sobre la ocupación de los yacimientos mesolíticos por parte de grupos neolíticos o, por el contrario, la presencia de cerámica en los grupos de cazadores-recolectores (casos del conchero das Amoreiras (Arnaud, 2000, 36; Diniz, 2010, 52-53), o de Medo Tojeiro (Lubell et al., 2007, 210; Nukushina, 2016, 46).

\subsection{Malacología}

El conjunto de items malacológicos documentados incluye especies de estuario como la almeja fina (Venerupis decussata), la almeja de burro (Mactra stultorum), el berdigón (Cerastoderma edule), ostras (Crassostrea angulata, Ostrea edulis), caracolas (Murex brandaris), cañadillas (Bolinus brandaris) y escaramujos o bellotas de mar (Balanus sp.). En muchos casos, los fragmentos de conchas aparecen muy concreccionados (Fig. 10).

\section{Huesos humanos}

En superficie fueron detectados varios fragmentos de huesos humanos, no datados, que pasamos a detallar en la Tabla 3.

El análisis preliminar del conjunto osteológico humano localizado en Cañada Honda permite la identificación ósea de al menos un individuo. Teniendo en cuenta la antigüedad y estado de conservación observado en los fragmentos de hueso, todos parecen corresponder a un adulto, de edad y sexo indeterminados. Estos elementos son indicadores de un posible componente funerario presente en Cañada Honda, aunque carecemos de una atribución cronológica precisa y de la ausencia de contexto debido a su carácter superficial. Cabe señalar que algunos fragmentos óseos están agrupados junto a restos de sedimento compactado, con presencia de conchas, como es apreciable en el caso de la mandíbula (Fig. 11).

La presencia de huesos humanos revela, una vez más, la necesidad de profundizar en el estudio de este yacimiento para poder inferir si estas evidencias de una posible asociación de prácticas funerarias con su ocupación prehistórica reflejarían 


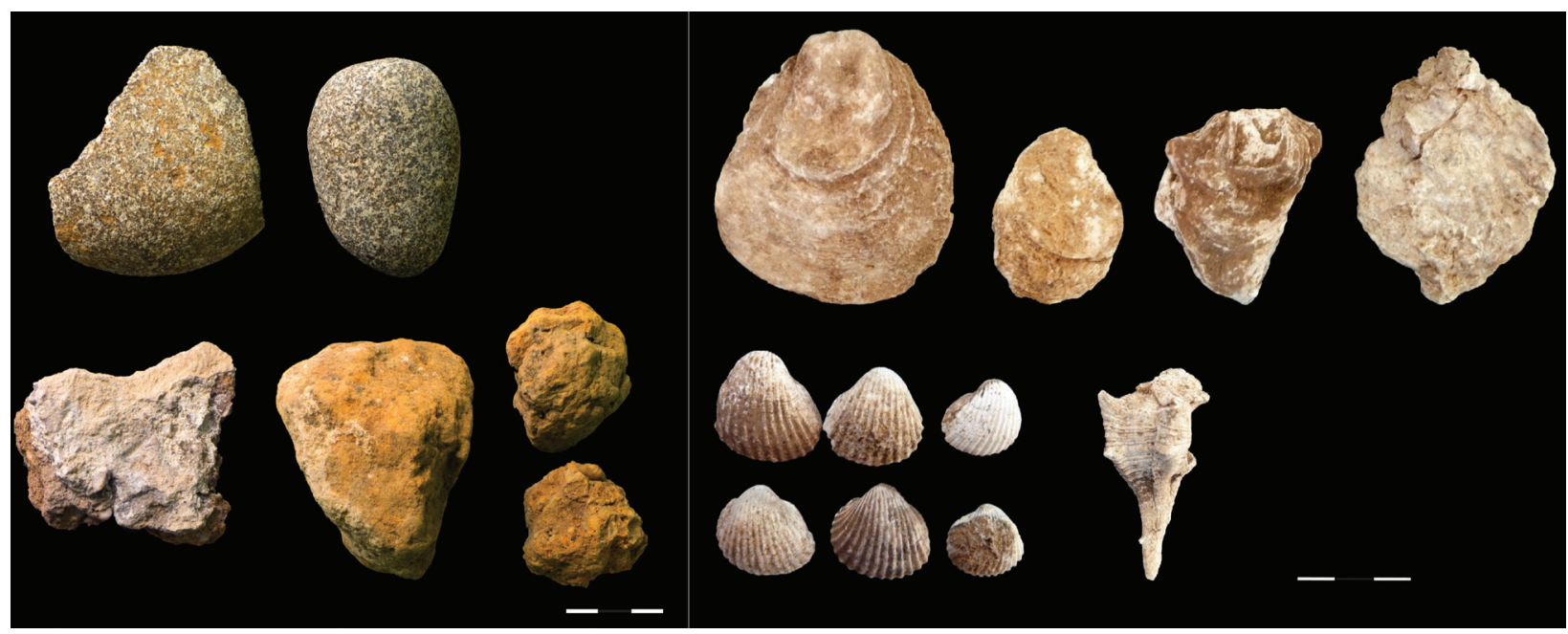

Fig. 10. Cantos en granito, nódulos de barro y muestra de especies malacológicas de Cañada Honda.

\begin{tabular}{llllll}
\hline Piezaósea & $\begin{array}{l}\text { Región } \\
\text { anatómica }\end{array}$ & Lado & $\begin{array}{l}\text { Edad dela } \\
\text { muerte }\end{array}$ & Sexo & Observaciones \\
\hline Mandíbula & $\begin{array}{l}\text { Fracción alveolar } \\
\text { correspondiente } \\
\text { a los dientes } 34 \mathrm{a} \\
38\end{array}$ & Izquierdo & Adulto & Indeterminado & $\begin{array}{l}\text { Presencia de un } \\
\text { ligero desgaste en } \\
\text { las partes dentales. }\end{array}$ \\
\hline Costillas & $\begin{array}{l}\text { Fragmentos de } \\
\text { arco }\end{array}$ & Indeterminado & $\begin{array}{l}\text { Posiblemente } \\
\text { adulto }\end{array}$ & Indeterminado & \\
\hline $\begin{array}{l}\text { Ulna o } \\
\text { cúbito }\end{array}$ & $\begin{array}{l}\text { Fragmento de } \\
\text { diáfisis }\end{array}$ & Indeterminado & $\begin{array}{l}\text { Posiblemente } \\
\text { adulto }\end{array}$ & Indeterminado & \\
\hline $\begin{array}{l}\text { Ulna o } \\
\text { cúbito }\end{array}$ & Tercio proximal & Izquierdo & $\begin{array}{l}\text { Posiblemente } \\
\text { adulto }\end{array}$ & Indeterminado & \\
\hline Fémur & $\begin{array}{l}\text { Fragmento de } \\
\text { diáfisis }\end{array}$ & Indeterminado & $\begin{array}{l}\text { Posiblemente } \\
\text { adulto }\end{array}$ & Indeterminado & \\
\hline Tibia & $\begin{array}{l}\text { Tercio distal da } \\
\text { diáfisis }\end{array}$ & Izquierdo & $\begin{array}{l}\text { Posiblemente } \\
\text { adulto }\end{array}$ & Indeterminado & $\begin{array}{l}\text { Presencia de } \\
\text { reacciónperióstica. }\end{array}$ \\
\hline Perone & $\begin{array}{l}\text { Fragmento de } \\
\text { diáfisis }\end{array}$ & Indeterminado & $\begin{array}{l}\text { Posiblemente } \\
\text { adulto }\end{array}$ & Indeterminado & \\
\hline $\begin{array}{l}\text { Huesos } \\
\text { largos }\end{array}$ & $\begin{array}{l}\text { fragmentos de } \\
\text { diáfisis }\end{array}$ & Indeterminado & $\begin{array}{l}\text { Posiblemente } \\
\text { adulto }\end{array}$ & Indeterminado & \\
\hline
\end{tabular}

Tabla 3. Material osteológico humano documentado en superfície en Cañada Honda (Clasificación basada según los criterios propuestos por Ferembach et alii, 1980; Herrmann et alii, 1990; Smith, 1984 e Hillson, 1996).

la existencia de una mayor complejidad en el tipo de asentamiento. Cabe señalar que el componente funerario de los concheros es ya conocido siendo un hecho que complica aún más su estudio, como ocurre en el sur de Portugal en los concheros de los ríos Sado (Arnaud, 1989; Arias et al., 2015; 2016; Diniz y Arias, 2012; Cunha y Umbelino, 2001; Peyroteo Stjerna, 2016) y en los de estuarios de los ríos Tajo - Muge (Roche, 1989, Bicho et al., 2010; $2013 ; 2017)$.

\section{Cronología}

Se ha obtenido una datación por radiocarbono (Sac-3060-Laboratorio de Datação por Radiocarbono-C2TN- Instituto Superior Técnico, Universidade de Lisboa), a partir de una muestra de conchas tomada en la vertiente Este de Cañada Honda, en el área del corte estratigráfico, en el nivel de base del conchero situado bajo un nivel con presencia de adobes, o de barro cocido o alterado por el fuego, que indica 


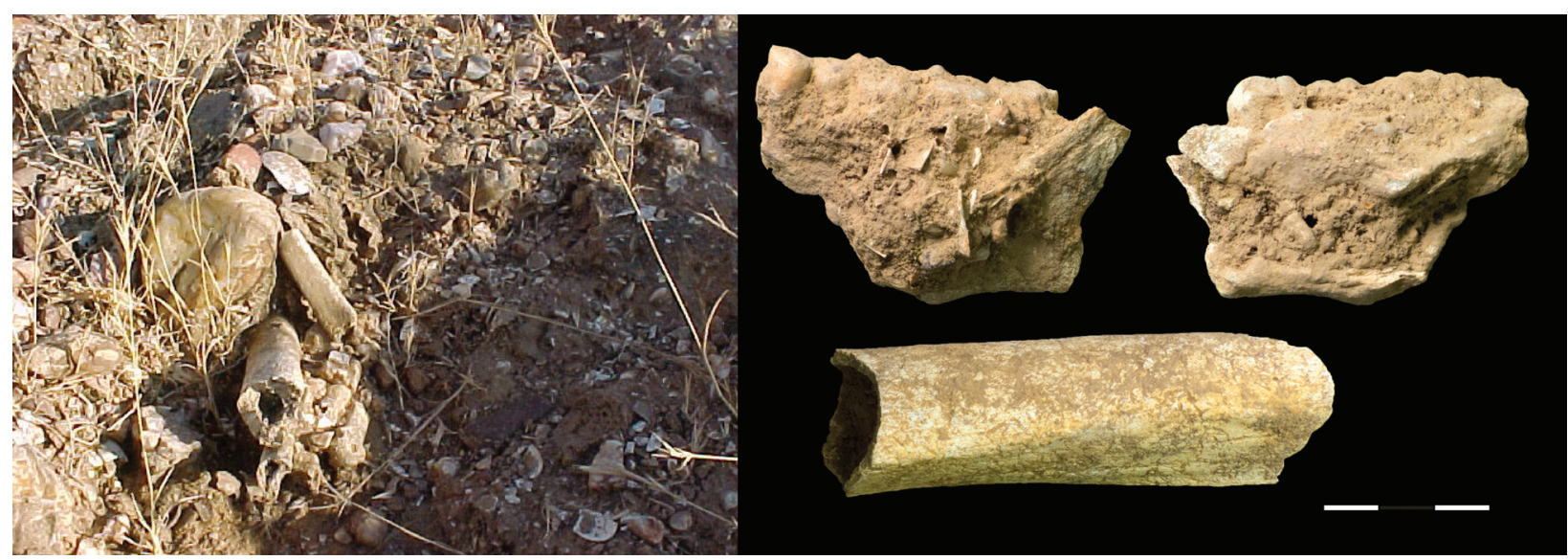

Fig. 11. Material osteológico humano.

un marco cronológico entre 5998-5724 cal a.C. $2 \sigma$. (Fig. 5, punto 2).

La atribución cultural de correspondencia de esta fecha sigue siendo desconocida, ya que proviene de una sola muestra del corte estratigráfico. Sin embargo, si la integramos en el contexto de las cronologías de la transición del Mesolítico al Neolítico Antiguo de Andalucía (Martín et al., 2017, 466), sugiere que es probable que dicha data de Cañada Honda apunte a un contexto mesolítico. A este respecto, las cronologías sobre la consolidación y generalización de las nuevas prácticas socioeconómicas se sitúan entre el 5500 y el 4750 cal a. C. E incluso es posible que los inicios de estas prácticas se remonten a fechas anteriores, como así vienen informando dataciones absolutas efectuadas en algunos yacimientos (Op. Cit., 466). En el contexto del debate sobre las formas de transición de las comunidades de cazadores-recolectores a las comunidades neolíticas, los concheros desempeñan un papel fundamental en la determinación de una "neolitización" a partir de un sustrato mesolítico o de una posible sustitución poblacional. Cabe señalar, sin embargo, que la mayoría de los datos sobre los inicios de los asentamientos sedentarios/ neolíticos en Andalucía proceden de contextos de cuevas, con muchos menos ejemplos de concheros y asentamientos al aire libre y además, en su mayor parte, de la zona sudoriental de Andalucía (Carrasco et al., 2016, 161ss; Camalich y Martín, 2013,105).

En la provincia de Cádiz, se han estudiado yacimientos que en su mayoría están situados al aire libre, con presencia o no de concheros, que son emblemáticos para el estudio de este periodo, como son Embarcadero del Río Palmones y El Retamar (Ramos, 2013, 82-83). A partir de los datos obtenidos en El Retamar, sus investigadores han constatado en el registro arqueológico una continuidad tecnológica en la industria lítica durante esta fase (Ramos, 2013, 83-84), con una fuerte presencia de microlitos geométricos, cerámica, áreas de actividad y consumo de alimentos identificadas y finalmente la presencia de enterramientos humanos. Se trataría de comunidades semisedentarias, en fase de transformación en sociedades tribales, insertas en un esquema de explotación territorial conectado con sitios ubicados en el interior (Muñoz, 2013, 84). Cabe señalar que este yacimiento ha proporcio-

\begin{tabular}{|c|c|c|c|c|c|}
\hline \multirow[b]{2}{*}{ Referencia Laboratorio } & \multirow[t]{2}{*}{ Tipo de muestra } & \multirow{2}{*}{$\begin{array}{r}\delta^{13} \mathrm{C} \\
(\% 0)\end{array}$} & \multirow{2}{*}{$\begin{array}{c}\text { Data 14C } \\
\text { (BP) }\end{array}$} & \multicolumn{2}{|c|}{ Data Calibrada } \\
\hline & & & & $1 \sigma$ & $2 \sigma$ \\
\hline Sac-3060 & Venerupis decussata & $-1,31$ & $7250 \pm 60$ & $5957-5806$ & $5998-5724$ \\
\hline
\end{tabular}

Tabla 4. Fecha de radiocarbono obtenida de una muestra de concha recogida en Cañada Honda (Calibración basada en la curva IntCal13 (Reimer et al, 2013) y el valor de $\Delta \mathrm{R}=-108 \pm 31$ años (Martins y Soares, 2013; Soares, 2015), usando el programa CALIB 7.0.0 (Stuiver y Reimer, 1993). 


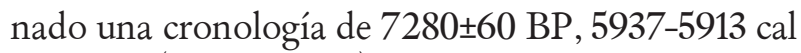

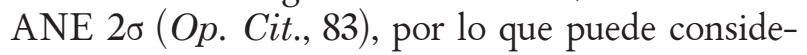
rarse contemporáneo de Cañada Honda.

Aunque los yacimientos tipo conchero son muy escasos en Andalucía, el conchero de Cañada Honda tiene muchas similitudes con los casos del Sado y el Tajo, como se ha mencionado anteriormente. Además de estos grandes grupos de concheros portugueses, ampliamente conocidos, se localizan otros más al sur de Portugal, como el conchero de Fiais, en el río Mira (González y Arnaud, 1990, 457; Lubell et al., 2007, 212-217) y de Paço Velho en la Ribeira de Seixe (Reis, 2013a, 312-313; Reis, 2013b, 72-75). El sitio de Fiais es otro ejemplo de conchero con presencia de prácticas funerarias, así como con indicadores de actividades asociadas a una intensa explotación de los ambientes estuarinos. El de Paço Velho 2, situado en la región meridional de Portugal, que ha sido descubierto recientemente, es un enclave con una implantación topográfica similar a algunos de los situados en el Sado, con un amplio dominio visual sobre el río, como ocurre en Cañada Honda, y en el que se han documentado materiales líticos característicos de la fase final del Mesolítico / Neolítico Antiguo que, además, ha proporcionado una datación absoluta, a partir de conchas recogidas en la superficie, que apunta a un posible marco cronológico entre 5519 - 5289 cal a.C. (fecha BP 6930 \pm 60 ) (Reis, 2013a, 312). La interpretación de esta data, con las debidas cautelas dado el contexto en el que se recogió la muestra, sugiere que este yacimiento puede haber desempeñado un papel importante en la transición económica y cultural entre el Mesolítico Final y el Neolítico Antiguo. En este estuario también se encuentra el sitio de Montes de Baixo, con un conchero cuyos niveles de ocupación datan de finales del VII / principios del VI milenio a.C. (Silva e Soares, 1997). Todavía en el litoral suroeste de Portugal, se pueden encontrar otros ejemplos de concheros o asentamientos con gran presencia de restos malacológicos con cronologías de comienzos del VI milenio a.C., como Samouqueira I (Soares y Silva, 2003, 46, 52; Lubell et al., 2007, 211-212), Rocha das Gaivotas (situada en el extremo suroeste de la región de Sagres-San Vicente) (Carvalho y Valente, 2005, 20-22; Carvalho, 2008, 196201; Carvalho, 2010, 57), asociados a la explotación de los recursos marinos y/o líticos. Medo Tojeiro, datado de mediados/finales del VI milenio a.C. (Silva et al., 1985; Lubell et al., 2007, 209-211), es otro yacimiento representativo cuya investigación será clave para entender mejor el proceso de neolitización en esta área (Reis, 2013b, 100). En el litoral meridional del Algarve, cabe mencionar la Ribeira de Alcantarilha, a la que se atribuye una cronología de fases posteriores asociadas al Neolítico Antiguo (Bicho et al., 2000, 20; Carvalho, 2010, 57; Reis, 2013b,102).

En el caso del sudoeste portugués, el cuadro cronológico parece apuntar a la existencia de un sustrato poblacional mesolítico en los yacimientos de Fiais, Samouqueira y Vidigal, que permanecerían ocupados hasta la segunda mitad del VI milenio cal. a.C., en los casos de Samouqueira y Vidigal y comienzos de la primera mitad del VI milenio cal. a.C., en el caso de Fiais (Reis, 2013b,104). Estos datos podrían ser indicadores de la "pervivencia de los sistemas sociales de cazadores-recolectores en el valle de Mira, hasta una etapa tardía, demostrando una continuidad cultural en esta región y revelando poca o ninguna adherencia a los elementos neolíticos que ya circulaban a lo largo de la costa sudoeste"[Traducción de los autores] (Reis, 2013b, 104). Un escenario similar ha sido sugerido para el grupo de concheros del Sado, donde las formas de vida del Mesolítico pervivirían hasta alrededor de 4750 cal. a. C. (Zilhão, 1998,41), mientras que en áreas litorales próximas ya existirían grupos en contextos propiamente del Neolítico (Reis, 2013b,104-106). De hecho, en el sur de Portugal, los primeros núcleos neolíticos se encuentran en el Algarve occidental y en Estremadura (Zilhão, 1993, 1997, 1998,2001; Carvalho, 2008).

6. EsQUEMA DE OCUPACIÓN PREHISTÓRICA DE LOS ESTUARIOS DE LOS Ríos TiNTO Y Odiel (VI-III MILENIOS)

De forma simultánea a Cañada Honda o en un momento inmediatamente posterior se va a producir un poblamiento significativo formado por hábitats, semisedentarios o permanentes, que evidencian el desarrollo de modos de vida neolíticos en el reborde costero de la gran bahía litoral que constituía la desembocadura de los ríos Tinto y Odiel. Estos grupos se establecen directamente en las orillas, sobre elevaciones de escasa entidad e incluso en su entorno continental inmediato a través de los valles fluviales inundados que confluían en los estuarios.

Sin duda, la bonanza de las condiciones climáticas y las buenas posibilidades subsistenciales de este entorno estuarino propiciaron dicha ocupación 
evidenciada en diversos tipos de yacimientos. Para tener una visión de conjunto amplia nos centraremos en un arco cronológico que abarca desde mediados del VI hasta finales del III milenio. Además de los concheros como Cañada Honda y El Grillito, las ocupaciones más antiguas como La Dehesa y, posiblemente, Sierra de la Calvilla -localización esta última algo más alejada en la actualidad del reborde del paleoestuario del Odiel- sí que parecen responder a pequeños poblados, semisedentarios como se ha propuesto para el caso concreto del primero citado (Camalich y Martín, 2013, 119). Sin embargo, hasta el presente son mejor conocidos y son más abundantes aquellos cuya implantación se desarrolla durante el III milenio a.n.e. Unos, de carácter más complejo, como Seminario-La Orden y Papa Uvas, que poseen características semejantes como demuestran su ubicación en zonas de cierta elevación con respecto a la línea de costa, las numerosas evidencias de aprovechamiento de los recursos marinos, la construcción de numerosas estructuras negativas, tales como silos, fondos de cabaña, hornos (Garrido y Vera, 2015, 152-3) y, en el caso del segundo, zanjas (Martín, 2018, 58-65; Martín y Jabalquinto, 2018, 123), y otro conjunto de yacimientos como Casa del Río, Huerta de la Fresa, El Rincón y El Tejar que también comparten similitudes con los precitados aunque su grado de conocimiento es inferior.

El conchero de El Grillito ${ }^{2}$ está situado a unos $9 \mathrm{~km}$ al $\mathrm{N}$ de Cañada Honda aguas arriba del Odiel

2 Las primeras menciones a El Grillito (Gibraleón) se refieren a un yacimiento adscrito al Paleolítico Medio (García, 1987, 22; García y Castiñeira, 1987, 33). Pocos años después se publica el yacimiento tipo conchero también denominado El Grillito (Borja, Barral y García, 1994, 348-351). A partir de los datos de localización, escasos y poco precisos, aportados sobre ambas localizaciones por sus investigadores, dada la evidente sinonimia y situación toponímica en el mismo término municipal de Gibraleón, se venía considerando que ambas localizaciones debían de estar muy próximas entre sí debido en parte a que en las citadas publicaciones no se hacían referencias mutuas entre ellas, pese a compartir idéntica denominación. Dos años después, en otro trabajo editado en 1996, en que se alude brevemente a los concheros del litoral onubense (García, Campos, Castiñeira, Gómez y Borja, 1996, 641), se hace una breve mención del conchero denominado "Instituto Nuevo", que sitúan en Gibraleón y, sin embargo, se omite la mención del conchero de El Grillito (Gibraleón), que ya había sido publicado, quedando sin aclarar si se trataba de dos yacimientos diferentes. Posteriormente, en varios inventarios de carácter interno realizados por la Consejería de Cultura y Patrimonio Histórico de Andalucía sólo consta en Gibraleón un conchero con la denominación de "Instituto Nuevo". Imprecisiones que han pervivido hasta en las proximidades de la localidad de Gibraleón, en lo que debió ser una amplia paleoensenada de la margen izquierda del rio. Los restos arqueológicos y malacológicos aparecen diseminados en unos 300 $\mathrm{m}^{2}$ de superficie (Borja et al., 1994, 341) sobre una terraza fluvial media a una altitud de 20 m.s.n.m., algo distante de las actuales marismas del rio (Fig. 12). El yacimiento está parcialmente desmontado por diferentes impactos que se han sucedido en el tiempo como son la extracción de áridos, el trazado del antiguo ferrocarril Huelva-Zafra y por los sucesivos ensanches de la carretera N-431 que discurre por su vertiente E. A través de un corte en uno de sus lados se ha podido analizar la estratigrafía del yacimiento que tiene una potencia algo menor de 1 $\mathrm{m}$. Aunque presenta dos niveles, sus investigadores han considerado que se trata de una única fase de ocupación antrópica. El nivel inferior está constituido fundamentalmente por gravas y una escasa presencia de conchas mientras que en el nivel superior además de las gravas son muy abundantes los restos malacológicos y la industria lítica (Borja et al. 1994, 350). En el citado nivel superior, o nivel 2 , que entra en contacto con la superficie del terreno, se documentó también una estructura siliforme de tipo cazoleta, qué penetra hasta el nivel infrayacente, "con relleno de cantos rotos, conchas de ostras y berberechos" (Borja et al. 1994, 345, foto 2).

El conchero Grillito/Instituto Nuevo, por tanto, presenta una menor complejidad que Cañada Honda ya que sólo se ha constatado en él la existencia de una única fase ocupacional en la que su industria lítica es de mediano y gran tamaño realizada sobre diversas materias primas, con predominio de núcleos discoides de preparación centrípeta y sus lascas resultantes. Se documentó también material pulimentado, un elemento pasivo de molino y escasas cerámicas, lo que llevó a plantear a su equipo investigador la existencia de una mayor diversificación de la actividad económica con una agricultura más desarrollada, atribuyéndole una cronología del III milenio, que consideraron contemporánea a la

que, durante los recientes trabajos de campo de la actividad arqueológica de actualización del Inventario de yacimientos arqueológicos de Gibraleón (Campos, 2017), hemos podido clarificar que El Grillito (conchero) e Instituto Nuevo (conchero) son el mismo yacimiento, de aquí que en lo sucesivo pasaremos a identificarlo como "Instituto Nuevo". Del mismo modo, también hemos inspeccionado el yacimiento paleolítico conocido como "El Grillito", que está situado a $1 \mathrm{~km}$. al S. del citado conchero ocupando, por tanto, distinto emplazamiento. 
unidad superior de Cañada Honda. Dichos autores, valorando también factores paleoambientales y geomorfológicos, van a situar los concheros de Cañada Honda y El Grillito/Instituto Nuevo en la segunda mitad del Holoceno, entre finales del Neolítico y el paso al Calcolítico, en que observan dos fases bien diferenciadas en el proceso de continentalización que registra la desembocadura del Odiel en la segunda fase del Holoceno. Dos momentos en que se constataría el paso de un ambiente de ensenada abierta al de un medio y un paisaje netamente estuarino de aguas más calmas y fondos en vías de colmatación por sedimentos finos (Borja et al., 1994, 351).

El poblado de La Dehesa (Lucena del Puerto, Huelva), se localiza en la margen derecha del Tinto sobre una colina amesetada muy próxima al estuario del Tinto (Fig. 12). Es el que ha proporcionado evidencias más claras de una adscripción cronocultural neolítica de las más antiguas del estuario, según su tipología cerámica y la industria lítica superficial (Piñón y Bueno 1985, 119ss; Piñón 1986, 53-55; Camalich y Martín, 2013, 119-122). En base a sus investigaciones a partir de un estudio de materiales procedentes de una recogida de carácter superficial, Piñón y Bueno proponen la existencia en La Dehesa de un neolítico litoral asimilable culturalmente al Neolítico Antiguo evolucionado del Alentejo portugués, que sitúan en el $\mathrm{V}$ milenio a.C. (Piñón y Bueno, 1985, 122), sobre cuyo sustrato se conformaría el poblamiento del Neolítico Final como el representado por Papa Uvas (Piñón, 1988, 246ss). Últimamente, otros autores le han atribuido una fecha de mediados del VI milenio, aunque hasta el presente no se han aportado dataciones absolutas (Camalich y Martín, 2013, 122). Éstos refuerzan su atribución cronológica en la valoración de la industria lítica microlítica, de tradición epipaleolítica, que relacionan con la fase más reciente del mesolítico del sur de Portugal, así como por sus cerámicas impresas cardiales y el uso del engobe de almagra, con paralelos en las de yacimientos de la bahía de Cádiz y área portuguesa entre el Tajo y el Algarve, con cronologías de la segunda mitad del VI milenio cal. a.C. (Camalich y Martín, 2013, 121).

La Sierra de la Calvilla (Gibraleón, Huelva), se asienta en el reborde de campiña próximo al cauce y a la antigua desembocadura del Odiel. Desde los años 70 se tenían noticias muy vagas sobre su localización (Garrido, 1975, 33). Según un reciente trabajo sobre el mismo puede considerarse como un hábitat neolítico con dos momentos de ocupación (Gavilán et al., e.p.) (Fig. 12). Sus inicios se datan en los momentos finales del V milenio, o Neolítico Antiguo ya muy avanzado, a juzgar por las cerámicas decoradas y parte de la industria lítica tallada, mientras que la presencia de formas carenadas denota una ocupación correspondiente a comienzos del IV milenio, al Neolítico Final o N.A.T. (Neolítico Atlántico Tardío) (Gavilán et al., 2009, 139; Gavilán et al., e.p.). En el yacimiento son abundantes los elementos de molturación, como los morteros y las piezas activas y pasivas de molino que permiten suponer, con reservas, determinadas prácticas agrícolas, en un entorno rodeado de tierras aptas para el cultivo y de varios cursos menores de agua. La proximidad a la antigua desembocadura del Odiel no permite descartar el aprovechamiento de recursos como la pesca y el marisqueo, además del beneficio que les aportaría la recolección y la caza (Gavilán et al., e.p.).

Seminario-La Orden (Huelva) se sitúa en la pequeña península situada en el centro de la ancha bahía litoral flandriense donde confluyen las desembocaduras de los ríos Tinto y Odiel (Fig. 12). Se han documentado ciertas estructuras funerarias perte-

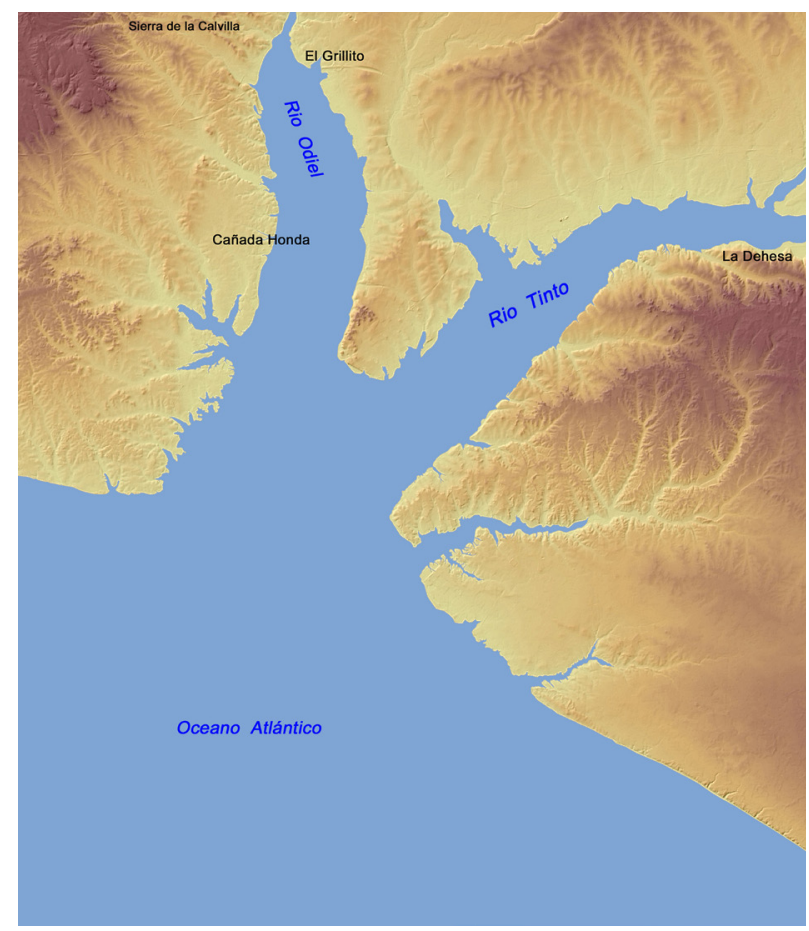

Fig. 12. Cañada Honda y yacimientos de los estuarios Tinto-Odiel hacia el VI-V milenio. 
necientes al IV milenio, aunque la mayor cantidad de información procedente de este yacimiento corresponde al III milenio a.C. y fases posteriores en un extenso continuum habitacional. Para la fase Neolítico Final en Seminario-La Orden se ha informado de una "ocupación continuada de su territorio entre el VI y el V milenios cal. BP." (Garrido y Vera, 2015, 149), donde destacan las estructuras negativas, silos y fondos de cabaña, basureros, enterramientos y depósitos rituales, que se distribuyen por una extensión que llega a las 23 ha. El yacimiento se prolonga hacia el N, S y E, y posiblemente englobe otros enclaves, como el desparecido de El Rincón, situado junto a las actuales marismas del rio Tinto (Garrido, 1971, 96-100) (Fig. 12).

Papa Uvas (Aljaraque), está enclavado en la margen derecha del paleoestuario del Odiel cercano a su desembocadura (Fig. 13). Es un yacimiento extenso en el que se han documentado estructuras de combustión tipo hornos/cocina, estructuras de habitación y de almacenamiento, así como zanjas (Martín, 1985, 184-6; 1986, 209-213; 2018, 58-65). Los inicios de Papa Uvas tienen lugar en el IV milenio a.C., momento en el que sus pobladores empiezan a excavar estructuras negativas circulares en cuyo interior se detecta la presencia de restos de moluscos y artefactos de piedra tallada y pulimentada, piezas activas y pasivas de molino, así como restos de ovicápridos, suidos, bóvidos y otros mamíferos. Esta base económica, centrada en la malacofauna, continúa a lo largo de las distintas fases a la que se suma la ganadería y no tanto la agricultura (Martín, 1994, 204-206; 1996, 8790; Martín y Jabalquinto, 2018, 118). No se han documentado estructuras funerarias.

Casa del Río (Aljaraque), se ha considerado un hábitat fluviomarino cuya localización se extiende a orillas del tramo final del arroyo del Valle próximo a su desembocadura en el estuario del Odiel (Fig. 13). En función de los restos materiales recuperados en su excavación se ha equiparado a la Fase I del cercano yacimiento de Papa Uvas (Martín y Campos, 1997, 286), mientras que otros autores remontan su cronología debido a la presencia de "un porcentaje relativamente alto de cerámicas decoradas coloca al yacimiento en una fase anterior a Papa Uvas” (García et al., 1997, 279). En Casa del Río se documentaron una serie de estructuras consistentes en "fondos de cabaña", estructuras de almacenamiento en cuyo interior aparecían ceni-

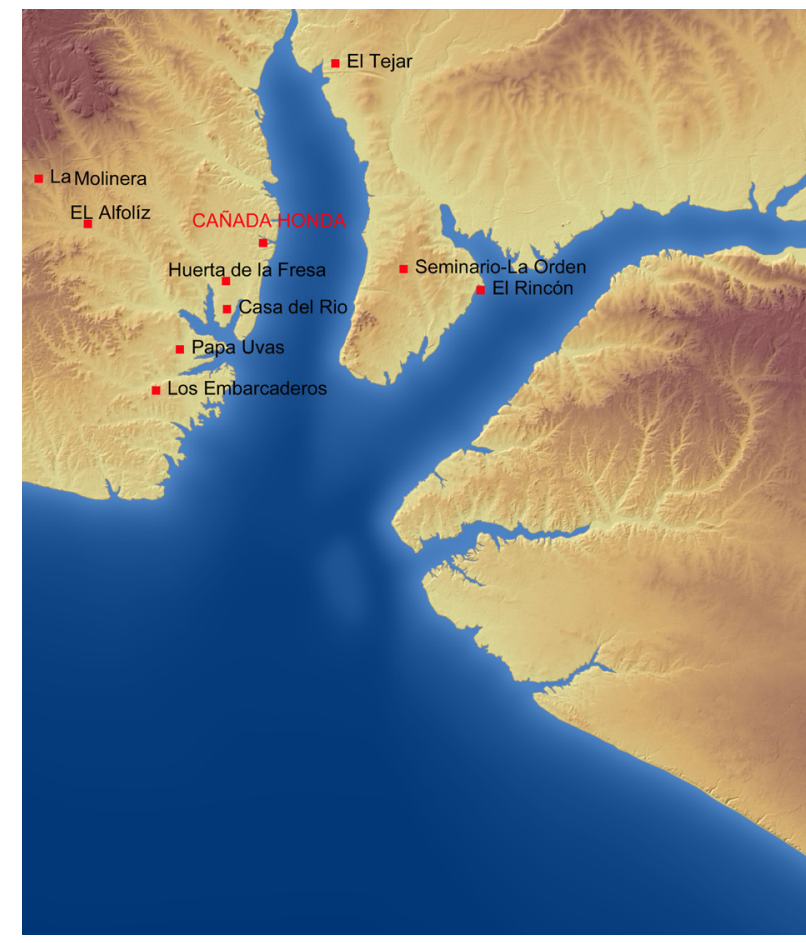

Fig. 13.Yacimientos de los estuarios Tinto-Odiel entre IV-II milenios.

zas y bivalvos, y un hogar, del que una muestra de carbón proporcionó una datación por Carbono 14 de $4400 \pm 140$ B.P. (Teledyne Brown Engineering, 1_17.726, en Martín y Campos, 1997, 282-285, figs. 3 ; 4A; 4B; 5A y 5B). Parte del sedimento fue sometido a flotación, recuperándose escasas evidencias de "especies de cultivo" (García et al., 1997, 276). El yacimiento ha sido interpretado como un poblado que se ocupa y abandona reiteradamente a partir del tipo de estructura habitacional presente en el yacimiento que, en los casos estudiados, poseen escasa potencia. En su industria lítica destaca un alto componente microlaminar en sílex, con presencia de geométricos.

Huerta de la Fresa es un yacimiento situado muy próximo a Casa del Río en el mismo contexto fluviomarino y con similares materiales, en el que se ha estimado la posibilidad de que forme parte de la misma ocupación de Casa del Río (Fig. 13). Entre sus materiales sobresale la presencia de pulimentados, hacha, azuela y piezas activas y pasivas de molinos, junto con núcleos y laminillas talladas en sílex, documentadas en el interior de una estructura habitacional tipo "fondo de cabaña" (Campos, 2007; e.p.) 
El Tejar(Gibraleón) ocupa un área relativamente extensa junto al Camino de Coronillas (Fig. 13). Ha proporcionado cerámicas consistentes en platos de borde engrosado y borde saliente, cuencos ovoides de borde entrante y otros de casquete esférico que nos remiten al Calcolítico (Pérez et al., 2002, 15-16; fig. 2). En un área más extensa se han documentado en superficie útiles pulimentados, núcleos y restos líticos de talla y escorias de sílice libre (Serrano et al., 560, fig. 6).

Otros yacimientos posiblemente coetáneos, que están en fase de estudio, se han documentado por los espacios prelitorales y litorales de la margen derecha del Odiel. En el término municipal de Aljaraque se encuentran La Molinera, Los Embarcaderos, Las Vegas y El Alfolíz (Campos, 2002, 131) (Fig. 13). Más al N. en el vecino término municipal de Gibraleón, en contextos fluviomarinos similares del río Odiel, se han documentado también nuevos yacimientos inicialmente adscritos al Neolítico, concretamente Cañada del Corcho y Arroyo del Prado, mientras que en la margen izquierda del Odiel se localizan Cantarranas-La Concepción (Campos, 2017) y ya en término municipal de Huelva, Rivera de Nicoba-Peguerillas (Martín y Campos, 1995, 18) (Fig. 13).

\section{ConCLUSIÓN}

Como hemos expuesto, el marco en el que tuvieron lugar los procesos de antropización de los estuarios de los ríos Tinto y Odiel desde inicios del Holoceno y a lo largo de la Transgresión Flandriense fue un territorio sujeto a una dinámica evolutiva que hoy conocemos mejor gracias a los avances producidos en las últimas décadas en la investigación geomorfológica de dicho espacio.

En el estado actual de nuestro conocimiento, el conchero de Cañada Honda, con su componente lítico, cerámico, óseo humano y posibles estructuras de almacenamiento y habitacionales, posee claros paralelos con los concheros portugueses ya citados de los ríos Sado y Tejo. Cañada Honda constituye, en esencia, un modelo de asentamiento representativo de una reestructuración poblacional que tiene lugar a principios del Holoceno cuando el hábitat experimenta un claro crecimiento en torno a los estuarios de los grandes ríos. Esta reestructuración se basa en la lógica del aprovechamiento de un ecosistema estuarino bastante rico en recursos naturales, en el que los medios de subsistencia malacológicos desempeñan un papel preponderante en las dietas. Este poblamiento podría constituir una red de asentamientos basada en una lógica de explotación logística del territorio. Sin embargo, se necesitan más datos para comprender mejor esta dinámica a escala regional.

La presencia de cerámica en Cañada Honda, sin contar en el presente con una contextualización precisa, representa una cuestión problemática, como ya hemos mencionado más arriba. Su constatación estratigráfica podría significar, por un lado, que el conchero se formó en una fase neolítica bastante antigua, mientras que, por otro lado, podría evidenciar también la existencia de contactos de comunidades mesolíticas con comunidades neolíticas. Tampoco deben excluirse las cuestiones tafonómicas, que podrían dar como resultado una contaminación de determinados niveles estratigráficos con material cerámico.

El poblamiento del Mesolítico-Neolítico Antiguo del área que ocupa el estuario del Odiel, apunta a una gestación a partir de un sustrato constituido por grupos de cazadores recolectores que a inicios de la Transgresión Flandriense desarrollarán nuevas estrategias de explotación de los recursos del estuario del Odiel, siendo el conchero de Cañada Honda el yacimiento paradigmático donde se han apreciado dichos cambios, con una cronología absoluta de inicios del VI milenio a.C., mientras que en el estuario del Tinto, peor conocido, se puede considerar La Dehesa como la localización arqueológica representativa de la implantación de un proceso de neolitización más avanzado, al que recientemente se ha atribuido una cronología del mediados del VI milenio (Camalich y Martín, 2013, 122).

En el desarrollo de dicho proceso en los siguientes milenios, V al III a.C., las localizaciones arqueológicas proliferan principalmente en el estuario del Odiel manteniendo, además, un similar patrón de asentamiento que generalmente prosiguen en contextos fluvio-marítimos. Factores determinantes fueron un ambiente climático adecuado para la implantación de hábitats al aire libre, la biodiversidad faunística y botánica, y el modelado físico de los estuarios, con condiciones de amplia bahía protegida de las corrientes oceánicas, con aguas remansadas y poco profundas que proporcionaban unas seguras bases subsistenciales en cuanto a pesca, marisqueo y caza, amén de una mayor diversificación económica con la ganadería y la agricultura. 
Hasta el Neolítico Final e inicios del Calcolítico el hábitat se mantendrá sin cambios apreciables, formado en su mayoría por poblados no muy extensos muchos de los cuales se han interpretado como asentamientos semisedentarios o de reocupación temporal. Sus construcciones generalmente estaban realizadas con ramas y cubiertas leñosas y con el empleo de adobes, estando presentes en dichos asentamientos estructuras negativas como fondos de cabaña, silos, basureros, hornos y zanjas.

El yacimiento de Papa Uvas, posiblemente el más investigado, es representativo del tránsito del Neolítico Final al Calcolítico en el contexto geográfico que nos ocupa. Muestra numerosas evidencias de una economía mixta en la que se conjugaron el uso de la ganadería y de la agricultura, la caza, la pesca y el marisqueo de productos marinos. Es un tipo de hábitat con ciertas similitudes al que se constata también en la margen izquierda del Odiel, en estructuras del Neolitico Final del yacimiento La Orden-Seminario, situado en la península donde se encuentra la ciudad de Huelva.

La presente aproximación al yacimiento de $\mathrm{Ca}$ ñada Honda, veinticinco años después de sus primeras noticias, suponen un intento de caracterización territorial y tecnocultural del yacimiento con la profundización en la singularidad de su utillaje lítico y otros ítems presentes en su estratigrafía. Además de ello, la datación de radiocarbono obtenida a partir de muestras de conchas de Venerupis decussata, obtenida de la base del nivel de mayor concentración de conchas de su estratigrafía (Fig. 5), nos ha facilitado, según hemos detallado ut supra, una datación absoluta de $7250 \pm 60 \mathrm{BP}$; 5998-5724 cal a.C 2。 (Sac 3060), lo que supone la fecha más antigua documentada hasta el presente de un asentamiento humano en el Estuario del Odiel. Dicha data establece un referente para el conocimiento de esta fase de la prehistoria en la ría de Huelva y Suroeste de la Península Ibérica.

El análisis de los datos disponibles de Cañada Honda denota su gran potencial para el estudio de la problemática inherente al estudio de los concheros, como marco de investigación territorial y como lugares de carácter simbólico. El posible componente funerario constatado en este yacimiento, de confirmarse, sería de gran importancia para la comprensión de los rituales funerarios de aquellas comunidades e incluso para el análisis isotópico, con vistas a la obtención de una mayor información sobre las paleodietas y la movilidad humana durante la prehistoria.

Para profundizar en numerosos aspectos de $\mathrm{Ca}$ ñada Honda ignotos o aún sólo percibidos y por su gran potencial será necesario realizar proyectos de investigación arqueológicos que integren trabajos en extensión. Sin duda, estamos ante un yacimiento clave para el estudio y definición de los modos de vida en el estuario del Odiel en el proceso de tránsito de las sociedades con economía cazadorarecolectora a aquellas con estrategias productoras y sedentarias.

\section{Agradecimientos:}

Queremos mostrar nuestro agradecimiento al Dr. Juan Antonio Morales González, del Departamento de Ciencias de la Tierra de la Universidad de Huelva, y al Dr. José Ojeda Zújar, del Departamento de Geografía Física y Análisis Geográfico Regional de la Universidad de Sevilla, por proporcionarnos la base cartográfica de la evolución geomorfológica de los estuarios Tinto y Odiel sobre las que hemos realizado las figuras 11 y 12 . Asimismo, nuestro agradecimiento a la Dra. Beatriz Gavilán Ceballos, del Departamento de Historia, Geografía y Antropología de la Universidad de Huelva, por facilitarnos la consulta de uno de sus artículos que aún permanece en prensa, así como al Dr. Juan Aurelio Pérez Macías, del Departamento de Historia, Geografía y Antropología de la Universidad de Huelva por su participación en las salidas de campo y consejos para la realización de este trabajo.

De igual forma, agradecemos su colaboración al Dr. António Monge Soares, del Centro de Ciências e Tecnologias Nucleares (C2TN), Departamento de Engenharia e Ciências Nucleares del Instituto Superior Técnico de la Universidad de Lisboa, por la obtención y calibración de la fecha de radiocarbono, así como a las Dras. Raquel Granja e Marina Lourenço, investigadoras independientes, por su contribución en la clasificación y descripción del material osteológico humano.

\section{BibliografiA}

Aguilar, M.E., Morales, J.A., Morales-Mateo, R., Feria, M.C., González, M.A. y González-Batanero, D. (2019), "Geometría de las unidades superiores del relleno holoceno del canal estuarino del Odiel (Huelva, SO de España)", Revista de la Sociedad Geológica de España, 32 (1): 127-142. 
Arias, P., Diniz, M., Araújo, A.C., Armendariz, Á. y Teira, L. (2015), "At the Edge of the marshes: new approaches to the Sado Valley Mesolithic (Southern Portugal)", Muge 150th: The 150th Anniversary of the Discovery of Mesolithic Shell middens, Cambridge Scholars Publishing, 1, 301-319.

Arias, P., Diniz, M., Cubas, M., Duarte, C., Iriarte, E., Salzmann, C., Teichner, F. yTeira, L. (2016), "Looking for the traces of the last hunter-gatherers: geophysical survey in the Mesolithic Shell middens of the Sado valley (southern Portugal)”, Quaternary International, (435), 61-70.

https://doi.org/10.1016/j.quaint.2016.02.016.

Araújo, A. (1995-1997),“A indústria lítica do concheiro de Poças de S. Bento (vale do Sado) no seu contexto regional”,O Arqueólogo Português, 13/15, 87-159.

Arnaud, J., (1989), "The mesolithic communities of the Sado Valley, Portugal, in their ecological setting”, The Mesolithic in Europe, III International Symposium (Bonsall, C., Ed.), John Donald, Edimburgo, 614-632.

Arnaud, J. (2000), "Os concheiros mesolíticos do vale Sado e a exploração dos recursos estuarinos (nos tempos pré-históricos e na actualidade)", Actas do Encontro sobre Arqueologia da Arrábida, Trabalhos de Arqueologia 14, Lisboa, 21-43.

Balbo, A., Madella, M., Godino, I. B. y Álvarez, M. (2011), "Shell midden research: An interdisciplinary agenda for the Quaternary and Social Sciences”, Quaternary International, 239 (12), 147-152.

Batanero Martín, C. (2016), Memoria de la Intervención Arqueológica Preventiva de prospeción superficial en la finca Manzorrales (Aljaraque) con motivo de la explotación de la gravera "Manzorrales II", efectuada por la empresa de arqueología ÁNFORA, en el año 2016, Delegación Provincial de Cultura en Huelva (Inédito).

Beltrán López, J.M., López Domínguez, M.A. y García Rincón, J. Ma . (1997), "Intervención arqueológica de urgencia en el entorno de Cañada Honda (Aljaraque, Huelva)", Anuario Arqueológico de Andalucía / 1993, III, 272-280.

Bicho, N.F.,Lindly, J.,Stiner, M. y Ferring, C.R. (2000), "O mesolítico e o Neolítico Antigo da Costa Algarvia” Muita gente, poucas antas?
Origens, espaços e contextos do Megalitismo, Actas do II Colóquio sobre Megalitismo. Instituto Português de Arqueologia, Lisboa, 15-22.

Bicho, N., Umbelino, C., Detry, C. y Pereira, T. (2010), "The emergence of Muge Mesolithic shell midens in central Portugal and the 8200 calyr BP cold event", Journal of Island and Coastal Archaeology, 5, 86-104.

https://doi.org/10.1080/15564891003638184.

Bicho, N., Cascalheira, J., Marreiros, J., Gonçalves, C., Pereira, T. y Dias, R. (2013), "Chronology of the Mesolithic occupation of the Muge valley, central Portugal: the case of Cabeço da Amoreira", Quaternary International, 308-309, 130-139.

https://doi.org/10.1016/ j.quaint.2012.10.049.

Bicho, N., Cascalheira, J., Gonçalves, C., Umbelino, C., Rivero, D.G. y André, L. (2017), "Resilience, replacement and acculturation in the Mesolithic/Neolithic transition: the case of Muge, central Portugal", Quaternary International, 446, 31-42. https://doi.org/10.1016/j. quaint.2016.09.049.

Borja Barrera F., Barral Muñoz, A., y García Rincón, J.M.; (1994), "Los concheros arqueológicos de Cañada Honda y El Grillito (Estuario del Odiel, Huelva)", Geomorfología en España: III Reunión de geomorfología, Vol. I (GómezVillar, García Ruíz y Arnáez Vadillo. Coords.), Zaragoza, 339-355.

Borja, F.; Zazo, C., Dabrio, C. J., Díaz del Olmo, F; Goy, J. L.; y Lario, J. (1999), "Holocene aeolian phases and human settlements along the Atlantic coast of southern Spain", The Holocene, 9, 3, 333- 339 .

Borrego, J., Ruiz, F., Gonzalez-Regalado, M.L., Pendón, J.G. y Morales, J.A. (1999), “The Holocene transgression into the estuarine central basin of the Odiel River mouth (Cadiz Gulf, SW Spain): lithology and faunal assemblages”, Quaternary Science Reviews, 18, 769-788.

Cáceres Puro, L.M. (1992), "Geomorfología del interfluvio Odiel-Piedras en su zona de desembocadura”, Cuadernos del Suroeste, 3, 57-88.

Cáceres Puro, L.M. (1995), Geomorfología del sector occidental de la depresión del Guadalquivir, Tesis Doctoral Universidad de Huelva. Huelva. 
Cáceres Puro, L.M. (1999), Geomorfología del sector occidental de la Depresión del Guadalquivir (Huelva), Huelva.

Camalich Massieu, Ma‥D. y Martín Socas, D. (2013), "Los inicios del Neolítico en Andalucía. Entre la tradición y La innovación”, Menga, 4, 103-129.

Campos Jara, P. (2002), "La Carta Arqueológica de Aljaraque (Huelva)”, Anuario Arqueológico de Andalucía/1999, II, 121-137.

Campos Jara, P. (2007), Memoria de la Actividad Arqueológica Preventiva en el P.P.R.11 de Aljaraque (Huelva). Sondeos arqueológicos en los yacimientos Rio Odiel I y Huerta de la Fresa, autorizada por la dirección General de Bienes Culturales en abril de 2006. Huelva/ Sevilla, Archivo de la Delegación Provincial de Cultura y de la Dirección General de Bienes Culturales de la Junta de Andalucía (Inédito).

Campos Jara, P. (2017), Inventario de los yacimientos arqueológicos situados en el término municipal de Gibraleón (Huelva), de apoyo a la documentación técnica para su inscripción en el C.G.P.H.A. (Avance), Delegación Provincial de Cultura de la Junta de Andalucía en Huelva (Inédito).

Campos Jara, P. (2018), "El paleolítico de Rio Odiel I: contribución al estudio de su definición estratigráfica”, Arqueología y Territorio en la provincia de Huelva: veinte años de las Jornadas de Aljaraque (1998-2017), Campos Jara, P. (Edit.), Huelva.

Campos Jara, P. (e. p.), “Actividad Arqueológica Preventiva en el PPR-12 de Aljaraque (Huelva). Yacimientos Rio Odiel I y La Almaína" (Realizada en 2006), Anuario Arqueológico de Andalucía, Sevilla.

Campos Jara, P. y Pérez Macías, J.A. (2018), "El poblamiento romano en la margen derecha de la desembocadura del rio Odiel: el Caño del Fraile (Aljaraque/Gibraleón, Huelva)", Atas do VIII Encontro de Arqueología do Sudoeste Peninsular, Serpa, 509-529.

Carrasco Rus, J., Morgado Rodríguez, A. y Martínez Sevilla, F. (2016), "Implantación y desarrollo de los grupos neolíticos del Sur de la Península Ibérica. Reflexiones sobre algunos modelos interpretativos desde los inicios del siglo XXI", Del Neolitic a l'edad del bronze en el Mediterrani Occidental, Estudis en Homenatge a Bernat Martí Oliver, TV SIP 119, 159-180.
Carvalho, A., (1998), Talhe da pedra no Neolítico antigo do Maciço Calcário das Serras d'Aire e Candeeiros (Estremadura portuguesa): um primeiro modelo tecnológico e tipológico, Lisboa.

Carvalho, A. F. (2008), A neolitização do Portugal meridional. Os exemplos do Maciço Calcário Estremenho e do Algarve Ocidental, Promontoria Monografica, 12, Faro.

Carvalho, A. (2010), "Chronology and geography of the Mesolithic-Neolithic transition in Portugal”, On Pre-and Earlier History of Iberia and Central Europe Studies in honour of Philine Kalb (Armbrueste, T. y Hegewisch, M., Eds.), Dien zur archäologie Europas, 11, 45-62.

Carvalho, A. y Valente, M. (2005), "Novos contextos conquíferos pré-históricosna Costa Vicentina”, Actas do 2. Encontro de Arqueologia do Algarve, Xelb, 5, 9-26.

Castiñeira Sánchez, J., García Rincón, J. M., Álvarez García, G. y Martín Gómez, J. (1988), “Estado actual de las investigaciones paleolíticas en la provincia de Huelva", Trabajos de Paleolítico y Cuaternario (Díaz, F. y Vallespí, E., Eds.), Sevilla, 7-25.

Castiñeira Sánchez, J., Álvarez García, G., García Rincón, J.M., Gómez Toscano, F. y Martín Gómez, J. (1989): "Evidencias paleolíticas en las terrazas de los ríos Tinto y Odiel (Huelva)", El Cuaternario en Andalucía Occidental (Acosta, J., Álvarez, G., Baena, R., Borja F., y Castiñeira, J., Coords.), Sevilla, 59-66.

Clemente, L., Menanteau, L., y Rodríguez Vidal J. (1985), "Los depósitos Holocenos en el estuario de los ríos Tinto y Odiel (Huelva, España)", $A c$ tas de la I Reunión del Cuaternario Ibérico, Cuaternario Ibérico, V (I), Huelva, 339-353.

Cunha, E. y Umbelino, C. (2001), "Mesolithic people from Portugal: an approach to Sado osteological series", Anthropologie, 39, 125.

Dabrio, C.J., Zazo, C., Lario, J., Goy, J. L, Sierro, F. J., Borja, F., González, J. A. y Flores J. A. (1999), "Secuencestratrigraphy of Holocene incised-valley fills and coastal evolution in the Gulf of Cádiz (Southern Spain)”, Géologieen Mijnbouw, 77, 263-281.

Dabrio, J.C., Boersma, J.R. y Fernández, J. (1982), "Evolución sedimentaria de la Flecha del Rompido (Huelva)", IX Congreso Nacional de Sedimentología, Salamanca, 329- 341. 
Dabrio, C., Zazo, C., Goy, J.L., Sierro, FJ., Borja, F.,Lario, J., González, J.A., y Flores, J.A. (2000), "Depositional history of estuarine infill during the last postglacial transgression (Gulfof Cádiz, Southern Spain)”, Marine Geology, 162, 381-404.

Delgado, J., Boski, T., Nieto, J.M., Pereira, L., Moura, D., Gomes, A., Sousa, C. y García-Tenorio, R. (2012), "Sea-levelrise and anthropogenic activities recorded in the late Pleistocene/Holocene sedimentary infill of the Guadiana Estuary (SW Iberia)", Quaternary Science Reviews, $33,121-141$

Diniz, M. (2007), O Sítio da Valada do Mato (Évora): Aspectos da neolitização no Interior, Sul de Portugal, Lisboa.

Diniz, M. (2010), "O concheiro mesolítico das Amoreiras (S. Romão doSado, Alcácer do Sal): o (outro?) paradigma perdido?", Os últimos caçadores-recolectores e as primeiras comunidades produtoras do sul da Península Ibérica e do Norte deMarrocos (Gibaja, J.; Carvalho, A., Eds.), Promontória Monográfica, 15, Faro, 49-61.

Diniz, M. y Arias, P. (2012). "Human settlement in the Sado Paleo-Estuary: some issues around Mesolithic Shell-Middens”, Mudanças ambientais e interação humana na Fachada Atlântica Ocidental, 139-158.

Diniz, M. y Nukushina, D. (2014), "Caçadores-recolectores no vale do Sado, ambiente, recursos e tecnologia lítica: o caso de Arapouco (Alcácer do Sal)", Estudos do Quaternário,11, 27-38

Domínguez-Bella, S., Ramos Muñoz, J. y Vijande Vila, E. (2016), "Materias primas silíceas en la Prehistoria del occidente de Andalucía", Cuadernos de Prehistoria y Arqueología de la Universidad de Granada, 26, 327-356.

Ferembach, D., Schwidetzky, I. y Stloukal, M. (1980), "Recomendations for age and sex diagnosis of skeletons", Journal of Human Evolution, 9 (7), 517-549

García Rincón, J.M. (1987), "Prospección arqueológica superficial del Paleolítico y Epipaleolítico de la provincia de Huelva", Anuario Arqueológico de Andalucía /1986, II, Sevilla, 23-53.

García Rincón, J.M. y Castiñeira Sánchez, J. (1987), "Paleolítico y Epipaleolítico en Huelva, Huelva y su Provincia, vol. 2. (Fernández Jurado, J., Edit.), Madrid. 7-38.
García Rincón, J.M. y Rodríguez Vidal, J. (1990), "El sondeo estratigráfico de La Glorieta (Punta Umbría, Huelva)", Huelva Arqueológica, XII, 380-399.

García Rincón, J.M., Campos Carrasco, J.M., Castiñeira Sánchez, J., Gómez Toscano, F. y Borja Barrera, F., (1996), "Aproximación al poblamiento neolítico de la tierra llana de Huelva", Rubricatum I, 2., I Congrès del Neolític a la Península Ibèrica de Gavá. Barcelona, 639-645.

García, J.M., Borja, F., Gómez, F., Beltrán J.M., López, J.A., Barral M.A., Gómez C. y Porras (1997), "Excavación arqueológica de urgencia en Casa del Río II. (Aljaraque, Huelva). El corte A.”, Anuario Arqueológico de Andalucía/ 1993, III, 273-279.

Garrido Roiz, J.P. (1971), "Los Poblados de Bronce I Hispánico del estuario del Tinto-Odiel y la secuencia cultural megalítica en la región de Huelva”, Trabajos de Prehistoria, 28, 93-118.

Garrido Roiz, J.P., (1975), "II. La Edad de la Piedra”, Huelva: Prehistoria y antigüedad, Madrid, 27-37.

Gavilán Ceballos, B.; Escacena Carrasco, J.L. y Rodríguez, J. (2009), "La ocupación neolítica de la Baja Andalucía entre el Guadiana y el Guadalquivir”, IV Encuentro de Arqueología del Suroeste Peninsular, Huelva, 134-173.

Gavilán Ceballos, B. Campos Jara, P. y Duclos de Navascués G., (e.p.), "La Sierra de la Calvilla: un yacimiento neolítico próximo a la paleodesembocadura del río Odiel (Gibraleón, Huelva)”, Actas del X Encuentro de Arqueología del Suroeste Peninsular. Zafra del 9 al 11 de noviembre de 2018.

Garrido Fernández E. y Vera Rodríguez J.C. (2015), "Análisis espacial, contextual y funcional de un conjunto de estructuras domésticas del III Milenio A.C. del yacimiento de La Orden-Seminario (Huelva)", Revista Atlántica-Mediterránea, 17, 149-159.

González Morales y M., Arnaud, J. (1990), "Recent research on the Mesolithic in the Iberian Peninsula”, Contributions to the Mesolithic in Europe, Leuven, Leuven University Press, 451461.

Gutiérrez-Zugasti, I.Andersen, S. H., Araújo, A. C., Dupont, C., Milner, N. y Monge Soares, A. M. (2011), "Shell midden research in Atlantic Europe: State of the art, research problems and 
perspectives for the future", Quaternary International, 239, 1-2, 70-85.

Herrmann, B.,Gruppe, G., Hummel, S.,Piepenbrink, H. y Schutkowski, H. (1990), Praehistorische, Anthropologie,Leitfaden der Fels-und Labormethoden,Berlin, SpringerVerlag.

Hillson, S. (1996), Dental Anthropology, Cambridge, Cambridge University Press.

Horowitz, A. (1981), "Exploración de la llanura costera de Huelva. 1. Geología y Paleoambiente", Exploración Arqueometalúrgica de Huelva (EAH), Blanco Freijeiro, A. y Rothemberg, B. (Eds.), Barcelona, 183-216.

Inizan, M.L., Reduron-Ballinger, M., Roche, H., Tixier, J.y Feblot-Augustins, J. (1999), Technology and terminology of knapped stone: Followed by a multilingual vocabulary - Arabic, English, French, German, Greek, Italian, Portuguese, Spanish, Nanterre.

López-González, N. (2009), Estudio de marcadores ambientales sedimentarios y geoquímicos en los sedimentos del Estuario de los ríos Tinto y Odiel, Tesis Doctoral, Universidad de Huelva. Huelva.

Lubell, D., Jackes M., Sheppard, P., RowleyConwy, P. (2007), "The MesolithicNeolithic in the Alentejo: archaeological investigations, 19841986", From the Mediterranian basin to the Portuguese Atlantic shore: Papers in Honor of Anthony Marks, Actas do IV Congresso de Arqueologia Peninsular, Promontoria Monográfica, Universidade de Faro, Faro, 209229.

Marchand, G. (2001), "Les traditions techniques du Mésolithique final dans le Sud du Portugal: les industries lithiques des amas coquilliers de Várzea da Mó et Cabeço do Rebolador (fouilles M. Heleno)", Revista Portuguesa de Arqueologia, 4(2), 47-110.

Martín de la Cruz J.C. (1985), Papa Uvas I. Aljaraque, Huelva. Campañas de 1976 a 1979, Excavaciones Arqueológicas en España, 136, Madrid.

Martín de la Cruz J.C. (1986a), Papa Uvas II. Aljaraque, Huelva. Campañas de 1981 a 1983, Excavaciones Arqueológicas en España,149, Madrid.

Martín de la Cruz, J.C. (1986b), “A proximación a la Secuencia de hábitat en Papa Uvas (Aljaraque, Huelva)", Homenaje a Luis Siret (1934-1984), Sevilla, 227-242.

Martin de la Cruz, J.C. (1993), "El poblamiento pre y protohistórico de Aljaraque, Huelva". Homenaje a José $M^{a}$ Blázquez (Mangas, J. y Alvar, J., Eds), Madrid, 217-242.
Martin de la Cruz, J.C. (1994a), El Tránsito del Neolítico al Calcolítico en el litoral del Suroeste peninsular, Excavaciones Arqueológicas en España, 169, Madrid.

Martín de la Cruz, J.C. (1994b), "Avance a la discusión sobre medio ambiente: La relación vegetación-fauna en el caso de Papa Uvas (Aljaraque. Huelva)", Arqueología en el entorno del bajo Guadiana (Campos, J.M. Pérez, J.A. y Gómez, F., Eds.), Huelva, 201-208.

Martín de la Cruz, J.C. (1996), “Alteraciones antrópicas del ecosistema: Indicadores arqueológicos según Papa Uvas (Aljaraque, Huelva)", Rubricatum, 1, I Congreso Internacional de Neolítico Peninsular, Gavá-Barcelona, 85-91.

Martín de la Cruz, J.C. (1998), "El poblamiento Pre y Protohistórico de Aljaraque. Huelva”, Homenaje a José $M^{a}$ Blázquez (Mangas, J. y Alvar, J., Eds.), Madrid, 217-242.

Martín de la Cruz, J.C. (2018), "Los tiempos de papa Uvas (Aljaraque, Huelva)", Homenaje a Juana Bedia (Pérez Iriarte, L. y García Rincón, Coords.), Sevilla, 57-71.

Martín de la Cruz, J.C. y Jabalquinto Expósito, I.M. (2018): "Los moluscos marinos en la dieta alimentaria de Papa Uvas (Aljaraque, Huelva)", Arqueología y Territorio en la provincia de Huelva: veinte años de las Jornadas de Aljaraque (1998-2017), Campos Jara, P. (Ed.), Huelva, 97-136.

Martín Gómez, J. y Campos Jara, P. (1995): “El conchero de "Cañada Honda" (Aljaraque, Huelva): estrategias predatorias y modelos en transición", Spal, 4, 9-24.

Martín Gómez, J. y Campos Jara, P. (1996). “El proceso de adquisición y consolidación de estrategias productivas en entornos fluviomarinos: el estuario Tinto-Odiel (Huelva) como referencia", Rubricatum, 1, I Congreso Internacional de Neolítico Peninsular, Gavá-Barcelona, 109-114.

Martín Gómez, J. y Campos Jara, P. (1997), “El poblado de Casa del Río, Aljaraque (Huelva): su inserción en el proceso de génesis y consolidación de estrategias productoras en el marco del Suroeste Peninsular”. Anuario Arqueológico de Andalucía/1993, III, 280-289.

Martín-Socas, D., Camalich Massieu, M., Caro Herrero, J. y Rodríguez-Santos, F.J. (2018), “The beginning of theNeolithic in Andalusia", Quaternary International, 470, 451-471. http:// dx.doi.org/10.1016/j.quaint.2017.06.057

Martins, J.M.M. y Soares, A.M.M. (2013), Marine Radiocarbon Reservoir Effect in Southern At- 
lantic Iberian Coast, Radiocarbon, 55(2-3), 1123-1134.

Menéndez Amor, J. y Florschultz, F. (1973), "Resultados del análisis paleobotánico de una capa de turba en las cercanías de Huelva (Andalucía)", Estudios Geológicos, XX, 183-186.

Morales González, J.M. y Borrego Flores, J. (2009), "El litoral de Huelva: fisiografía y dinámica", Geología de Huelva (Abad de los Santos, M., Ed.), Huelva, 28-34.

Morales González, J.A. y Ojeda Zújar, J. (2010), "Evolución geomorfológica de la Ría de Huelva”, Huelva Marítima y Minera, 1929, Colección Agua, Territorio y Ciudad, 3, (FernándezPalacios Carmona, J.M., Dir.), Sevilla, 32-37.

Morgado, A., y Lozano, J. A. (2014), "Objetos de sílex, marcadores litológicos de la circulación. Geoarqueología de la producción laminar especializada del sur de Iberia (c. VI-V mil. cal. BP)", Movilidad, Contacto y Cambio: Actas del II Congreso de Prehistoria de Andalucía (García Alfonso, E., Ed.), Junta de Andalucía, Sevilla, 121-136.

Moro Berraquero, F.J. (2009), "Intervención arqueológica puntual en el yacimiento río Odiel I (Aljaraque, Huelva). modo 2 y modo 4 sobre la terraza media t.5 del río Odiel", Anuario $A r$ queológico de Andalucía/2004, 1, 1620-1630.

Muñoz, J. R., Vila, E.V., Duarte, J.C., Rodríguez, M. P., Salvador, D.B. y López, J.G. (2013), "Las sociedades tribales neolíticas en la zona litoral e interior de Cádiz. Continuidad poblacional y proceso histórico", Menga, 4, 79-102.

Nocete, F., Álex, E., Nieto, J.M., Sáez, R., Inácio, N. y Bayona, M., (2004-5), "Intensidad e intensificación en la primera minería y metalurgia del cobre especializada de la Península Ibérica (III milenio ane): la identificación arqueológica de un proceso regional de deforestación y polución”, Revista Atlántica-Mediterránea de Prehistoria y Arqueología Social, 7, Cádiz, 33-49.

Nukushina, D. (2012), Tecno-tipologia lítica e cronometria no Mesolítico final do vale do Sado o caso do concheiro das Amoreiras(Alcácer do Sal), Tese de Mestrado apresentada à Faculdade de Letras da Universida de de Lisboa.

Nukushina, D. (2016), "The Mesolithic-Neolithic transition through the Iberian shell middens - a review of current evidence andinterpretations", Entre ciência e cultura: Da interdisciplinaridade à transversalidade da arqueologia. Actas das VIII Jornadas de Jo- vens em Investigação Arqueológica (Coelho, I.; Torres, J.; Gil, L. y Serrão; T., Eds.) (Colecção ArqueoArte, 4),Lisboa, 43-51.

Ojeda Zújar, J. (1989), "La dinámica litoral reciente en la costa occidental de Andalucía”, El Cuaternario en Andalucía Occidental (Díaz del Olmo, F. y Rodríguez Vidal, J. Eds.), AEQUA, Monografías, 1, 123-132.

Paskoff, R., (1985), Les Littoraux, Paris.

Pérez Macías, J.A., Campos Carrasco, J. y Toscano Gómez, F. (2002), "El poblamiento de la Edad del Cobre en la Tierra Llana de Huelva", Huelva en su Historia, 9, 9-34.

Peyroteo Stjerna, R.(2016), On Death in the Mesolithic: Or the Mortuary Practices of the Last Hunter-gatherers of the South-Western Iberian Peninsula, 7th-6th Millennium BCE. DIVA.

Piñón Varela, F. (1986), "El Neolítico en Huelva”. Huelva y su Provincia, vol. 2, (Fernández Jurado, J., Dir.), Madrid, 42-65.

Piñón Varela, F. (1988), "El poblamiento neolítico de la orla litoral onubense: estado de la cuestión", Congreso Internacional sobre el Estrecho de Gibraltar, Madrid: 221-253.

Piñón Varela, F. y Bueno Ramírez, P. (1985), "Estudio de las colecciones de materiales procedentes de la Dehesa (Lucena del Puerto) y el Judío (Almonte): testimonios sobre la ocupación neolítica del litoral onubense”, Huelva Arqueológica, VII, 107-159.

Raposo, L. (1994): "O sítio de Palheirões do Alegra e a questão do Mirense”, Arqueología en el entorno del Bajo Guadiana (Campos, J.M., Pérez, J.A. y Gómez, F., Eds), Sevilla, 55-69.

Ramos Muñoz, J., Vila, E.V., Duarte, J.C., Rodríguez, M. P., Salvador,D.B. y López, J.G. (2013), "Las sociedades tribales neolíticas en lazona litoral e interior de Cádiz. Continuidad poblacional y proceso histórico", Menga, 4, 79-102.

Reimer, P.J., Bard, E., Bayliss, A., Beck, J.W., Blackwell, P.G., Bronk Ramsey, C., Buck, C.E., Cheng, H., Edwards, R.L., Friedrich, M., Grootes, P.M., Guilderson, T.P., Haflidason, H., Hajdas, I., Hatté, C., Heaton, T.J., Hoffmann, D.L., Hogg, A.G., Hughen, K.A., Kaiser, K.F., Kromer, B., Manning, S.W., Niu, M., Reimer, R.W., Richards, D.A., Scott, E.M., Southon, J.R., Staff, R.A., Turney, C.S.M. y van derPlicht, J. (2013), "IntCal13 and Marine13 Radiocarbon Age Calibration Curves, 0-50,000 Years cal BP”. Radiocarbon, 55 (4), 1869-1887.

Reis, H. (2013a), "Paisagens partilhadas? Novos dados sobre opovoamento Mesolítico e Neolítico 
antigo na costa Sudoeste alentejana”, I Congresso da Associação dos Arqueólogos Portugueses, Lisboa, 311-318.

Reis, H. (2013b), O povoamento Mesolítico e Neolítico Antigo no vale do Mira, no seu contexto regional, Tese de Mestrado apresentada à Faculdade de Letras das Universidade de Lisboa.

Reis, H. (2014), “The Mesolithic - Neolithic transition on the South-western Portuguese coast: preliminary data on the shell midden of Paço Velho 2", Des techniques aux territoires : nouveaux regards sur les cultures mésolithiques, Actes de la table-ronde, 22-23 novembre 2012, Maison de la recherche, Toulouse (France), Henry A., Marquebielle B., Chesnaux L., Michel S. (Dirs.), P@lethnologie, 6, 154-160.

Roche, J., (1989), "Spatial organization in the Mesolithic sites of Muge, Portugal", The Mesolithic in Europe, III International Symposium (Bonsall, C., Ed.), John Donald, Edimburgo 607-613.

Rodríguez Ramírez, A. (1996), "Holocene coastal progradation changes and peat bog development in SW Spanish Coast", International Union for Quaternary Research (INQUA), Subcommission on Mediterranean and Black Sea Sherolines (MBSS), Newsletter 18, 13-17.

Rodríguez Vidal, J. (1987), "Modelo de evolución geomorfológica de la Flecha Litoral de Punta Umbría, Huelva, España”, Cuaternario y Geomorfologia, 1, 247-256.

Rodríguez Vidal, J. y Vera Rodríguez, J.C. (2016), "Geoarqueología en el estuario de Huelva: evolución Holocena y poblamiento", Geoguías, 10, 217-243.

Serrano Pichardo, L., Campos Jara, P. y Pérez Macías, J.A. (2015), "A propósito de dos nuevas localizaciones de época prerromana en la desembocadura del Río Odiel (Huelva): las Monizas II y Gibraleón”, VII Encuentro de Arqueología del Suroeste Peninsular, (Medina Rosales, N., Coord.), Aroche (Huelva).

Smith, H. (1984), "Patterns of molar wear in hunter-gatherers and agriculturalists", American Journal of Physical Anthropology, 63, 39-56.

Silva, C. T.; Soares, J.; Penalva, C. (1985) - Para o estudo das comunidades neolíticas do Alentejo litoral: o concheiro do Medo Tojeiro. Arqueologia, 11, Porto, 5-15.

Silva, C. T.; Soares, J.; Penalva, C. (1997) - Economias costeiras na Pré-História do Sudoeste Português: o concheiro de Montes de Baixo. Setúbal Arqueológica, 11-12. Setúbal, 69-108.
Soares, A.M.M. (2015), "Radiocarbon dating of marine shells from the Gulf of Cadiz: the marine radiocarbon reservoir effect, its variability during the Holocene and palaeoenvironmental inferences", Cuaternario y Geomorfologia, 29 (1-2), 19-29.

Soares, J., Silva, C.T. (2003) "A transição para o Neolítico na costa Sudoeste portuguesa”, Muita gente, poucas antas? Origens, espaços e contextos do Megalitismo. II Colóquio Internacional sobre Megalitismo (Gonçalves, $V$. Eds.), Lisboa, Instituto Português de Arqueologia, Trabalhos de Arqueologia, 25, 45-56.

Stevenson, A.C. (1985), "Studies in the vegetational history of SW Spain. II. Palynological investigations at Laguna de las Madres, SW Spain”, Journal of biogeography, 12, 4 (Jul. 1985), 293-31

Vallespí Pérez, E., Álvarez García, G. y Del Amo y de la Hera, M. (1981), "Primeras evidencias paleolíticas de la provincia de Huelva”, Huelva Arqueológica, 5, 9-30.

Vallespí Pérez, E., Álvarez García, G., Pérez Sindreu, F.P. y RufeteTomico, P. (1986), "Nuevas atribuciones onubenses al Paleolítico Inferior y Medio", Huelva en su historia, 1, 43-56.

Vera, J.C., Linares, J.A., Martín, D., Camalich, Ma D. y González, P. (2010), "Los inicios de la producción de alimentos en Huelva, pasado y presente", Os últimos caçadores-recolectores e as primeiras comunidades produtoras do sul da Península Ibérica e do norte de Marrocos (Gibaja, J.F. y Faustino, A., Eds.), Faro, 119-130. Viguier, C. (1974), Le Néogéne de l'Andalousie Nord-occidentale (Espagne). Histoire géologique du Bassin du Guadalquivir, Tesis Doctoral, Universidad de Burdeos.

Tixier, J., Inizan, M.-L. y Roche, H., (1980), Préhistoire de la Pierre Taillé: économie du débitage laminaire, Paris.

Zazo, C., Goy, J.L., Somoza, L., Dabrio, C.J., Belloumini, G., Improta, S, Lario, J., Bardají, T., y Silva, P.G. (1994), "Holocene secuence of sea level fluctuations in relation to climatic trands in the Atlantic-Mediterranean linkage coast”, Journal of Coastal Research, 10 (4), 933-945.

Zazo, C.,Lezine, A.M., Borja, F.,Denefle, M.,Dabrio, CJ., Lario, J., Rodríguez Vidal, J., Goy, J.L., Díaz Del Olmo, F.,Cáceres, L., Clemente, L.,Baeteman, C., y Rodríguez Ramírez, A. (1996), "Holocene coastal progradation changes and peat bog development in SW Spanish Coast.”, International Union for Quaternary Research (INQUA), 
Subcommission on Mediterranean and Black Sea Sherolines (MBSS), Newsletter 18, 13-17.

Zazo, C., Dabrio, C.J., Borja, F., Goy, J.L., Lezine, A.M., Lario, J., Polo, M.D., Hoyos, M. y Boersma, J.R. (1999), "Pleistocene and Holocene Aeolian facies on the Huelva coast Southern Spain: climatic and neotectonics implications", Geologie in Mijnbouw, 77, 263-281.

Zilhão, J. (1993), “The spread of agro-pastoril economies across Mediterranean Europe: a view from the far west", Journal of Mediterranean Archaeology, 6 (1), 5-63.

Zilhão, J. (1997), O Paleolítico Superior da Estremadura portuguesa, Lisboa.

Zilhão, J. (1998), "A passagem do Mesolítico ao Neolítico na costa do Alentejo", Revista Portuguesa de Arqueologia, 1:1, 27-44.

Zilhão, J. (2001), "Radiocarbon evidence for maritime Pioneer colonization at the origins of farming in West Mediterranean Europe", Proceedings of the National Academy of Sciences, 98, 14180-14185. 
